\title{
First in situ Temperature Quantification of CoMoS species \\ upon Gas Sulfidation enabled by New Insight on Cobalt Sulfide Formation
}

\author{
L. PLAIS ${ }^{1,2}$, C. LANCELOT ${ }^{1}$, C. LAMONIER ${ }^{1}$, E. PAYEN ${ }^{1}$, V. BRIOIS ${ }^{2, *}$ \\ 1- Univ. Lille, CNRS, Centrale Lille, ENSCL, Univ. Artois, UMR 8181 - UCCS - Unité de \\ Catalyse et Chimie du Solide, F-59000 Lille, France \\ 2- Synchrotron SOLEIL, CNRS-UR1, BP 48, L'orme des Merisiers, Gif-sur-Yvette, France
}

\section{*Corresponding Author}

\begin{abstract}
Insights into the cobalt sulfide formation upon sulfidation $\left(10 \% \mathrm{H}_{2} \mathrm{~S} / \mathrm{H}_{2}\right)$ of cobalt-based materials with 4 wt \% $\mathrm{CoO}$ supported on alumina or silica were obtained by Quick-X-ray absorption spectroscopy monitoring analysed by multivariate curve regression analysis. A common pathway is evidenced involving the formation of supported defective $\operatorname{CoS}_{2}$ species transformed around 200$250^{\circ} \mathrm{C}$ into supported $\mathrm{Co}_{9} \mathrm{~S}_{8}$ species. Upon cooling down under sulfiding atmosphere, a reverse transition towards $\mathrm{CoS}_{2}$ was observed by XAS multivariate analysis and supported by Raman analysis. This reverse transition is sensitive to the $\mathrm{Co}_{9} \mathrm{~S}_{8}$ crystallite size: the smaller the $\mathrm{Co}_{9} \mathrm{~S}_{8}$ nanoparticles the higher the amount of formed $\mathrm{CoS}_{2}$ after cooling. The knowledge gained on the sulfidation of monometallic cobalt-based catalysts has been used in order to isolate the X-ray absorption spectrum of the CoMoS active species formed during the sulfidation of a calcined cobalt-promoted HDS catalyst. The evolution of the concentration of the CoMoS species upon temperature increase is determined for the first time, together with those of the pristine oxidic CoMo catalyst and $\mathrm{CoS}_{2}$ and $\mathrm{Co}_{9} \mathrm{~S}_{8}$ supported species. Although the conversion of $\mathrm{Co}_{9} \mathrm{~S}_{8}$ into $\mathrm{CoS}_{2}$ is still observed for the HDS catalyst when temperature is decreased under $\mathrm{H}_{2} \mathrm{~S} / \mathrm{H}_{2}$ atmosphere, no change of the CoMoS percentage is evidenced.
\end{abstract}

Keywords: $\mathrm{Co}_{9} \mathrm{~S}_{8} ; \operatorname{CoS}_{2}$; cobalt promoted HDS Catalyst; Raman; Quick-XAS

\section{Introduction}

Supported cobalt sulfides have been studied for decades as heterogeneous catalysts in several reactions such as hydrogenolysis of dimethyl disulfide to methanethiol [1, 2], but mainly because they are present in the hydrotreating (HDT) processes [3]. In the latter case, during sulfidation treatment of oxidic CoMo precursors, $\mathrm{CO}_{9} \mathrm{~S}_{8}$ is mainly reported as monometallic species formed in competition [4] with the CoMoS active phase described since the Topsoe works as MoS $\mathrm{M}_{2}$ slabs decorated at the corner and edge by cobalt atoms [5]. Recently, cobalt sulfides have attracted also overwhelming research interests as efficient electrocatalysts for oxygen evolution reaction (OER) [6, 7], oxygen reduction reaction (ORR) [8] or hydrogen evolution reaction (HER) [9-12]. The interest for the use of cobalt sulfides is the quest of earth-abundant electrocatalysts which can rival the efficiency of costly noble metal-based materials [13] and improve the long-term stability of the devices for large scale commercial applications. 
The binary Co-S phase diagram presents several bulk phases stable below $600{ }^{\circ} \mathrm{C}$ such as $\mathrm{Co}_{9} \mathrm{~S}_{8}, \mathrm{Co}_{3} \mathrm{~S}_{4}$ and $\mathrm{CoS}_{2}$ [14]. $\mathrm{CoS}_{2}$ and $\mathrm{Co}_{9} \mathrm{~S}_{8}$-based materials are the most studied electrocatalysts but with inequal consistency related to their structural identification. On the one hand, most of the characterizations done on $\operatorname{CoS}_{2}$-based electrocatalysts $[8,9,12,15]$ are consistent with the reported bulk $\operatorname{CoS}_{2}$ characterizations, using either X-ray diffraction (XRD) or short range order technique like Raman spectroscopy [16]. On the other hand, when $\mathrm{Co}_{9} \mathrm{~S}_{8}$-based samples are reported as electrocatalyst active phases, their poor crystallinity related to their high dispersion on support and/or nanometricsized structure hinders conventional identification by XRD. Short range order techniques such as Xray Absorption (XAS) and Raman spectroscopies are then used for identification of those different phases [17-23]. However, the claimed fingerprints used in Raman spectroscopy for identifying $\mathrm{Co}_{9} \mathrm{~S}_{8}$ in most of those papers show large discrepancies in the wavenumber of the related lines, making difficult to use them further as reference spectra for identification. Although appropriate synthesis conditions can easily yield to large crystals of $\mathrm{Co}_{9} \mathrm{~S}_{8}$ species $[24,25]$, the reason for the discrepancy in reported Raman fingerprints could be found in the lack of Raman spectrum reported in the literature for bulk $\mathrm{Co}_{9} \mathrm{~S}_{8}$ for which the structure has been certified by XRD.

Additionally, the description of the sulfidation of monometallic cobalt or nickel oxidic species is of prime importance to better understand the sulfidation of bimetallic $\mathrm{Co}(\mathrm{Ni}) \mathrm{Mo}$ oxidic precursors used for hydrodesulfurization (HDS) processes due to the competitive formation of monometallic sulfide species with the $\mathrm{Co}(\mathrm{Ni}) \mathrm{MoS}$ active phase. We have previously reported that during sulfidation of nickel oxidic precursors supported on alumina, several nickel sulfides are involved [26]. The high sensitivity of XAS for monitoring in situ phase transitions associated to chemometric analysis [27] to disentangle the complexity of phase mixture during transition were unique for reporting the XAS spectra of two pure nickel sulfides supported on alumina with $\mathrm{NiS}_{2}$ and $\mathrm{Ni}_{3} \mathrm{~S}_{2}$ compositions. $\mathrm{NiS}_{2}$ is first formed before being abruptly transformed in $\mathrm{Ni}_{3} \mathrm{~S}_{2}$ around $250^{\circ} \mathrm{C}$. This phase transition is accompanied by a strong release of $\mathrm{H}_{2} \mathrm{~S}$ and consumption of $\mathrm{H}_{2}$ as commonly reported in Temperature Programmed Sulfidation (TPS) analysis of mono and bimetallic HDS catalysts [28]. We study herein by Quick-EXAFS spectroscopy combined to Multivariate Curve Regression with Alternating Least Square (MCR-ALS) fitting analysis the fate of cobalt oxidic precursors (4 wt \% CoO) supported on alumina and silica upon sulfidation under $\mathrm{H}_{2} \mathrm{~S} / \mathrm{H}_{2}$ gaseous mixture. The goal is to reveal potential intermediate cobalt sulfide species before the formation of $\mathrm{Co}_{9} \mathrm{~S}_{8}$ and accordingly similarity between sulfidation of monometallic nickel (already reported in [26]) and cobalt precursors. Two supports were investigated in order to confirm or refute the single phase dispersion of $\mathrm{Co}_{9} \mathrm{~S}_{8}$ at the end of sulfidation. The speciation measured at RT under inert atmosphere will be in particular important for comparison purpose with previous results. For instance, using RT ${ }^{59} \mathrm{Co} N M R$ characterizations, Ledoux et al. [29] reported for silica Co supported catalyst with low loading a distorted octahedral site, which was assumed as a new sulfide species, coexisting with $\mathrm{Co}_{9} \mathrm{~S}_{8}$. Comparison will be also of prime importance with results obtained by the RT X-ray Photoelectron Spectroscopy (XPS) analysis most currently carried out today [30].

Finally, the knowledge gained on the sulfidation pathways of supported Co oxidic precursors will be used to solve the composition of sulfide cobalt-based species formed by sulfidation of a calcined cobalt promoted molybdenum-based HDS catalyst. To this purpose, the sulfidation of this catalyst will be alternately monitored by quick-EXAFS at the Mo and Co K edges using the unique capability of the ROCK beamline of SOLEIL synchrotron [31]. The MCR-ALS analysis of the evolution of Co K edge XAS data recorded upon sulfidation of the HDS catalyst precursor will be carried out through the simultaneous analysis of the data set recorded for the monometallic cobalt species previously 
studied and the one recorded for the HDS catalyst, assuming that both samples share common monometallic sulfide species. By this approach, we will isolate the XAS spectrum characterizing the active CoMoS species and report for the first time the in situ temperature quantification of the CoMos species during sulfidation. The cobalt speciation at $400^{\circ} \mathrm{C}$ and after decreasing the temperature at RT will be also discussed.

\section{Experimental}

\subsection{Samples preparation}

Preparation of bulk crystalline $\mathrm{Co}_{9} \mathrm{~S}_{8}$ was carried out by heating bulk crystalline $\mathrm{CoS}_{2}$ from Alfa Aesar (99.5\%) from RT to $450^{\circ} \mathrm{C}$ under $0.5 \% \mathrm{H}_{2} \mathrm{~S}-\mathrm{H}_{2}$ gaseous mixture.

Dried Co oxidic samples were prepared by incipient wetness impregnation of $5 \mathrm{~g}$ of $\gamma$ alumina trilobe extrudates (specific surface of $260 \mathrm{~m}^{2} / \mathrm{g}$ and pore volume $1 \mathrm{~mL} / \mathrm{g}$ ) or $5 \mathrm{~g}$ of silica (specific surface of $140 \mathrm{~m}^{2} / \mathrm{g}$ and pore volume $1.6 \mathrm{~mL} / \mathrm{g}$ ) with 5 or $8 \mathrm{~mL}$ of an aqueous solution containing $0.854 \mathrm{~g}$ of $\mathrm{Co}\left(\mathrm{NO}_{3}\right)_{2} \cdot 6 \mathrm{H}_{2} \mathrm{O}$, respectively. This preparation allows us to get $4 \mathrm{wt} \%$ of $\mathrm{CoO}$ on the supports. After maturation in a saturated water atmosphere at RT for $4 \mathrm{~h}$, the samples were dried at $100^{\circ} \mathrm{C}$ for $11 \mathrm{~h}$ under static air leading to so-called dried $\mathrm{Co} / \mathrm{Al}_{2} \mathrm{O}_{3}$ and dried $\mathrm{Co} / \mathrm{SiO}_{2}$ samples. Part of the dried samples was calcined at $500^{\circ} \mathrm{C}$ under air flow for $2 \mathrm{~h}$ with a heating ramp of $1^{\circ} \mathrm{C} /$ min leading to the so-called calcined $\mathrm{Co} / \mathrm{Al}_{2} \mathrm{O}_{3}$ and calcined $\mathrm{Co} / \mathrm{SiO}_{2}$ samples.

A CoNiMo/ $/ \mathrm{Al}_{2} \mathrm{O}_{3}$ oxidic $\mathrm{HDS}$ catalyst precursor containing 14 wt $\%$ of $\mathrm{MoO}_{3}$ was prepared by incipient wetness impregnation of the same $\gamma$ alumina trilobe extrudates with an aqueous solution of ammonium heptamolybdate, cobalt nitrate and nickel nitrate in the ratios $\mathrm{Co} / \mathrm{Mo}=0.27$ and $\mathrm{Ni} / \mathrm{Mo}=0.09$. After maturation in a saturated water atmosphere at $\mathrm{RT}$ for $5 \mathrm{~h}$, the samples were dried at $100^{\circ} \mathrm{C}$ for $12 \mathrm{~h}$ under static air before calcination at $480^{\circ} \mathrm{C}$ under air flow for $3 \mathrm{~h}$ with a heating ramp of $1^{\circ} \mathrm{C} / \mathrm{min}$.

\subsection{Samples sulfidation}

Sulfidation of the monometallic samples was carried out either using the high temperature Harrick cell [32] suitable for Raman spectroscopy measurements or the SAXO cell described in [33] for XAS ones. About $45 \mathrm{mg}$ of powdered samples were loaded in the respective cavities of the cells. Irrespective to the techniques, as the same quantity of samples is loaded in both cells, the flow of gases is identical and equal to $10 \mathrm{~mL} / \mathrm{min}$ of $10 \% \mathrm{H}_{2} \mathrm{~S} / \mathrm{H}_{2}$ mixture atmosphere mixture. Sulfidation of the different supported oxidic cobalt precursors was carried out heating the samples from RT to $400^{\circ} \mathrm{C}$ at 3 or $5^{\circ} \mathrm{C} / \mathrm{min}$ followed by a plateau of $30 \mathrm{~min}$ at $400^{\circ} \mathrm{C}$. The gases at the cell outlet were analysed by an online quadrupole mass spectrometer (Cirrus MKS). Sulfidation of the calcined CoNiMo oxidic precursor (22 mg) supported on alumina was carried out using the SAXO cell [33] with a heating ramp from $\mathrm{RT}$ to $400^{\circ} \mathrm{C}$ at $3^{\circ} \mathrm{C} / \mathrm{min}$ under $10 \mathrm{~mL} / \mathrm{min}$ of $10 \% \mathrm{H}_{2} \mathrm{~S}-\mathrm{H}_{2}$ mixture followed by a plateau of $2 \mathrm{~h}$ at $400^{\circ} \mathrm{C}$.

\subsection{Characterization}

In situ Raman spectra were acquired using a $532 \mathrm{~nm}$ RXN1 Raman spectrometer (Kaiser Optical Systems, Incorporation) equipped with a long working distance objective (Mitutuyo, x20) facing perpendicularly the $1 \mathrm{~mm}$-thick quartz window confining the reactive $\mathrm{H}_{2} \mathrm{~S} / \mathrm{H}_{2}$ atmosphere in the Harrick cell [30]. The nominal laser power was $11 \mathrm{~mW}$. Ex situ Raman were measured under air using 
a $785 \mathrm{~nm}$ RXN1 Raman spectrometer (Kaiser Optical Systems, Incorporation) coupled to an optical microscope (x10 magnification).

Co K-edge XAS data were recorded on the ROCK beamline at the SOLEIL synchrotron [31]. Time resolved in situ Quick-XAS measurements were performed in transmission mode with 3 ionization chambers filled with gaseous $\mathrm{N}_{2}$. The $\mathrm{Si}(111)$ channel-cut crystal was tuned to a Bragg angle near to the Co K-edge energy $\left(14^{\circ}\right)$ whereas the cam-driven tilt table supporting the channel-cut was allowed to oscillate with an amplitude of $2.3^{\circ}$ around this value and a frequency of $2 \mathrm{~Hz}$ allowing us to obtain each second 2 spectra with upward Bragg angles and 2 spectra with downward Bragg angles. The monochromator was energy-calibrated by setting the first inflection point of the K-edge spectrum of a standard metallic cobalt foil at $7709 \mathrm{eV}$ and the reference foil was continuously measured to correct monochromator energy drift. Twenty spectra collected with upward Bragg angles and previously interpolated in a common energy grid were merged to improve the signal-to-noise ratio leading to a time resolution of $10 \mathrm{~s}$ per presented spectrum during sulfidation.

The monitoring of the sulfidation of the $\mathrm{CoNiMo} / \mathrm{Al}_{2} \mathrm{O}_{3}$ catalyst was carried out using the edgejumping capability available at the ROCK beamline [31,34] with the alternate acquisition of Co and Mo K edge data as previously described in [34]. Frequency of the Si(220) channel cut oscillation used for Mo K edge recording was also $2 \mathrm{~Hz}$. Data at both edges were alternately recorded for $28 \mathrm{~s}$ with in between a blind period of $30 \mathrm{~s}$ used for changing monochromators, stripes of the harmonic rejection mirrors and ionization chambers. A common 2.75 mrad grazing incidence of the beam on the mirrors was used at both edges, but with exchange of the mirror stripes from $\mathrm{B}_{4} \mathrm{C}$ to $\mathrm{Pd}$ coating when changing from Co to Mo K edges, respectively.

XRD patterns of bulk cobalt sulfides and supported cobalt sulfide on silica were recorded in ambient conditions using the $\mathrm{Cu}$ K $\alpha$ radiation $\left(\lambda=1.5418 \AA\right.$ ) on a Bruker D2 phaser diffractometer, with a $0.05^{\circ}$ scan step and $2 \mathrm{~s}$ time step. To preserve the samples from reoxidation, they were loaded in a glove box in an airtight sample holder. The average crystallite size (D) of $\mathrm{CoS}_{2}$ and $\mathrm{Co}_{9} \mathrm{~S}_{8}$ was evaluated by the Scherrer's equation, $D=0.9 \lambda / \beta \cos \theta$ where $\beta$ is the full width at half-maximum of the most intense reflection.

The XPS sampling of the sulfided catalyst was performed in a glove box under argon atmosphere, with controlled oxygen and water level (less than $20 \mathrm{ppm}$ ) in order to avoid their partial reoxidation. The sample was crushed and pressed onto an indium foil that was attached to the sample holder via a double side carbon tape. The sample holder, thanks to the special connection of the glove box to the XPS spectrometer, was then moved in a transfer chamber for a first vacuum pumping before its introduction in the analysis chamber. The XPS spectra were recorded on a Kratos Axis Supra instrument with Al monochromator source $(1486.6 \mathrm{eV})$ and a hemi-spherical analyser operating at fixed pass energy of $20 \mathrm{eV}$. The measurements were made at RT in steps of $0.05 \mathrm{eV}$ for cobalt and 0.1 $\mathrm{eV}$ for sulfur, and at a pressure close $10^{-9}$ Torr in the sample analysis chamber. Binding energies (BE) of the elements are referenced to the $C 1 \mathrm{~s}$ level of the contamination carbon at $284.6 \mathrm{eV}$. The curves were integrated applying a Shirley type baseline. The collected spectra were analysed by using CasaXPS software, Version 2.0.71. The decomposition of the Co $2 p$ and S $2 p$ spectra were performed using the appropriate Gaussian-Lorentzian (GL30) contributions or asymmetric ones $(\operatorname{LA}(1.2,5,5))$ for the main Co $2 p_{3 / 2}$ and Co $2 p_{1 / 2}$ levels according to their metallic character [35]. 


\subsection{XAS data analysis}

Normalization of the XAS data recorded during in situ sulfidation was performed by using the Python normal_gui graphical user interface developed at SOLEIL for the fast handling of the Quick-XAS data. This interface has been recently described in [36]. The normalized experimental XAS spectra are then concatenated in ascending time of sulfidation in a matrix, $D$, and processed by MCR-ALS analysis [27, 37] which decomposes $\boldsymbol{D}$ into a matrix $\boldsymbol{C}$ containing the concentration of the $n$ pure species involved in the reaction and a matrix $\boldsymbol{S}^{T}$ containing the normalized XAS spectra of the pure species according to the equation:

$$
D=C S^{T}+E
$$

where the matrix $E$ contains the experimental noise. The rank of matrix $D$, i.e. $n$, is first determined by Principal Component Analysis (PCA), which is a dimensionality-reduction method allowing to reduce the number of highly correlated spectra contained in $\boldsymbol{D}$ into a smallest number of components explaining most of the $\boldsymbol{D}$ variance. Then MCR-ALS minimization is carried out considering the number of species known and starting for the minimization with an initial guess of the matrix of concentration derived by Evolving Factor Analysis [38]. After successive loops, leading to the alternate minimization of $\boldsymbol{S}$ and $\boldsymbol{C}$ matrices, iterations are stopped when the convergence criterion is achieved. For suppressing rotational ambiguity leading to non-unique mathematical solutions determined by MCR-ALS [37], physically and chemically meaningful constraints are used such as non-negativity of the absorbances contained in $\boldsymbol{S}$ and of the concentrations in $\boldsymbol{C}$, closure constraint for the concentrations (mass balance). One of the parameter used to measure the fit quality of the MCR-ALS solution is the Lack Of Fit, LOF (\%), defined as follows:

$$
\operatorname{LoF}(\%)=100 \sqrt{\frac{\sum_{i j} e_{i j}^{2}}{\sum_{i j} d_{i j}^{2}}}
$$

where $d_{i j}$ is an element of $\boldsymbol{D}$ ( $\mathrm{i}^{\text {th }}$ spectrum at the energy value $\mathrm{j}$ ) and $e_{i j}$ is the related residual value obtained from the difference between $\boldsymbol{D}$ and the rebuilt data over the n components from the $\boldsymbol{C} . \boldsymbol{S}^{T}$ matrix product obtained by MCR-ALS. $e_{i j}$ is calculated according to the relation:

$$
e_{i j}=d_{i j}-\sum_{k=1}^{n} C_{i k} \cdot S_{k j}^{T}
$$

where $C_{i k}$ is an element of $\boldsymbol{C}, S_{k j}$ an element of $\boldsymbol{S}$ and the sub-index $\mathrm{k}$ is related to the index of the component isolated by MCR-ALS.

For the XAS spectrum with index $\mathrm{i}$ in the matrix $\boldsymbol{D}$, a $R_{f}$ factor can be calculated according to the relation:

$$
R_{f}^{(i)}(\%)=100 \sqrt{\frac{\sum_{j} e_{i j}^{2}}{\sum_{j} d_{i j}^{2}}}
$$

Details about the use of PCA and MCR-ALS methods applied to XAS data can be found in references [26, 36, 39-40]. MCR-ALS minimizations on time-resolved XAS data presented herein were carried out using the MCR-ALS 2.0 gui developed on Matlab platform by the Roma Tauler's group [41].

The EXAFS oscillations were extracted from the normalized Co Kedge XAS data using the Athena graphical Interface software [42]. The EXAFS data were Fourier transformed using a $\mathrm{k}^{3}$-weigthing Kaiser Bessel window ( $\mathrm{dk}=2$ ) over the 2.8-10.6 $\AA^{-1} \mathrm{k}$-range. EXAFS fitting of distances, coordination numbers and Debye-Waller factors was performed with the Artemis interface to IFeFFIT using leastsquares refinements, firstly checked on a $\mathrm{CoO}$ standard [43] and bulk $\mathrm{CoS}_{2}$ [44], for which coordination numbers and distances are known. The use of those references allows us to determine 0.71 as value for the passive electron reduction factor $\mathrm{S}_{0}^{2}$. 


\section{Results}

\subsection{Raman characterization of bulk $\mathrm{Co}_{9} \mathrm{~S}_{8}$}

Bulk crystalline $\mathrm{Co}_{9} \mathrm{~S}_{8}$ was prepared by solid-gas reaction of commercial $\mathrm{CoS}_{2}$ under sulfiding atmosphere.

The purity of $\mathrm{CoS}_{2}$ was first analysed by XRD and XAS. Figures S1 to S3 in supporting information display the XRD pattern of $\operatorname{CoS}_{2}$ and XAS analysis for this sample recorded under inert atmosphere. The diffraction peaks in Figure $\mathrm{S} 1$ can be indexed with the hkl reflections of cubic pyrite-like structure [44] reported for $\operatorname{CoS}_{2}$ in the JCPDS card $n^{\circ} 41-1471$. The mean size of the $\operatorname{CoS}_{2}$ crystallites was determined at $\approx 48 \mathrm{~nm}$ using the Scherrer's formula. The XANES spectrum reported for $\operatorname{CoS}_{2}$ in Figure S2 displays the characteristic broad spectral shape of cobalt sulfide species with no white line [45, 46]. The ill-defined pre-edge structure assigned to transition from cobalt $1 \mathrm{~s}$ atomic level to $3 \mathrm{~d}$ molecular orbitals hybridized with metal $p$ states is characteristic of the octahedral symmetry in which cobalt atoms are embedded in the $\mathrm{CoS}_{2}$ structure $[45,46]$. A satisfactory simulation of the EXAFS signal in the 1-4 Å R-space (Figure S3, Table S1) has been obtained using the crystallographic distances reported for $\mathrm{CoS}_{2}[44]$.

The phase obtained by solid-gas reaction of crystalline $\operatorname{CoS}_{2}$ under $0.5 \% \mathrm{H}_{2} \mathrm{~S}-\mathrm{H}_{2}$ was ex situ characterized by XRD and XAS at RT. The diffraction pattern recorded for this phase (Figure S4) is consistent with the formation of $\mathrm{Co}_{9} \mathrm{~S}_{8}$ (JCPDS 86-2273) and a mean crystallite size around $67 \mathrm{~nm}$. The XANES spectrum (Figure S5) is well in line with the spectra reported in the literature for $\mathrm{Co}_{9} \mathrm{~S}_{8}[39,46]$ with a more resolved and intense pre-edge feature compared to $\operatorname{coS}_{2}$, which is ascribed to the increase of $3 d-4 p$ atomic orbital hybridization since cobalt sites characterizing $\mathrm{Cog}_{9} \mathrm{~S}_{8}$ are essentially non centrosymmetric (8 sites in tetrahedral symmetry for 1 site in octahedral ones) [45- 47]. The simulation of the EXAFS signal in the 1-6 ̊̊ R-space (Figure S6, Table S2) fully confirms the formation of bulk $\mathrm{Co}_{9} \mathrm{~S}_{8}$.

The solid-gas reaction of $\operatorname{CoS}_{2}$ under sulfiding atmosphere was in situ monitored by Raman spectroscopy. Figure 1 displays the Raman spectra recorded at RT before solid-gas reaction, at $450^{\circ} \mathrm{C}$ and at RT after cooling down the as-prepared $\mathrm{Co}_{9} \mathrm{~S}_{8}$. The measurements being carried out under reactive atmosphere $\left(\mathrm{H}_{2} \mathrm{~S} / \mathrm{H}_{2}\right)$, the lines at 355 and $588 \mathrm{~cm}^{-1}$ marked by a star are characteristic of gaseous $\mathrm{H}_{2}$ [40]. The RT Raman spectrum of $\mathrm{CoS}_{2}$ displays a main intense line located at $390 \mathrm{~cm}^{-1}$ characteristic of the $A_{g}$ mode associated to the in-phase stretching vibrations of sulfur atoms in the disulfide ligands of $\operatorname{CoS}_{2}$ [16]. The line at $286 \mathrm{~cm}^{-1}$ and shoulder at $417 \mathrm{~cm}^{-1}$ emerging slightly from the noise on Figure 1 are associated in the literature to $E_{g}$ and $T_{g}(2)$ modes of $\operatorname{CoS}_{2}$ corresponding respectively to the pure librational mode of the disulfide ligands and out-of-phase stretching vibrations of sulfur atoms in disulfide [16]. Actually those modes are more intense using a $785 \mathrm{~nm}$ laser excitation wavelength (Figure S7). It is noteworthy that irrespective of the excitation wavelength, a shift of the $\mathrm{CoS}_{2}$ lines to lower wavenumber is observed when $\mathrm{H}_{2} \mathrm{~S} / \mathrm{H}_{2}$ atmosphere is replaced by $\mathrm{N}_{2}$ (Figure $\mathrm{S} 8$ (a)). The RT Raman spectrum of bulk $\mathrm{Co}_{9} \mathrm{~S}_{8}$ under sulfiding atmosphere (Figure 1) displays two lines, a main line at $400 \mathrm{~cm}^{-1}$ and another one with lower intensity at $336 \mathrm{~cm}^{-1}$. As for $\mathrm{CoS}_{2}$, the change of atmosphere from $\mathrm{H}_{2} \mathrm{~S}$ to $\mathrm{N}_{2}$ leads on the spectrum of $\mathrm{Cog}_{9} \mathrm{~S}_{8}$ to a shift of these lines to 392 and $332 \mathrm{~cm}^{-1}$ (Figure S8 (b)). To the best of our knowledge, among dozens of papers [19-23] where lines mostly located above $500 \mathrm{~cm}^{-1}$ were attributed to $\mathrm{Cog}_{9} \mathrm{~S}_{8}$, only one [17] reported recently similar line positions to the ones published herein for bulk $\mathrm{Co}_{9} \mathrm{~S}_{8}$, with a small shift 
which could be ascribed to the atmosphere at which measurements were carried out (unfortunately not specify in [17]).

Finally, under a given atmosphere, herein $\mathrm{H}_{2} \mathrm{~S} / \mathrm{H}_{2}$, a shift of the $\mathrm{Co}_{9} \mathrm{~S}_{8}$ lines towards low wavenumbers is evidenced when the temperature is increased. At $400^{\circ} \mathrm{C}$, for instance, the main line is located at $386 \mathrm{~cm}^{-1}$ with a broad shoulder at $323 \mathrm{~cm}^{-1}$ instead of 400 and $336 \mathrm{~cm}^{-1}$ at RT (Figure 1). This shift monitored during the temperature decrease (Figure S9) from $450^{\circ} \mathrm{C}$ to RT varies linearly with the temperature. Taking into account the aforementioned variation of line positions of $\mathrm{Co}_{9} \mathrm{~S}_{8}$ and the Raman spectrum of $\mathrm{CoS}_{2}$, for which we verified that the position of the lines does not change with heating in this temperature range, we determined that only the broad line around $330 \mathrm{~cm}^{-1}$ can be used as a fingerprint of the formation of $\mathrm{Co}_{9} \mathrm{~S}_{8}$. Figure 2 reports a 2D evolution of its Raman spectra intensity as a function of the temperature. The onset of $\mathrm{Co}_{9} \mathrm{~S}_{8}$ formation from heating of $\mathrm{CoS}_{2}$ under sulfiding atmosphere is determined around $200^{\circ} \mathrm{C}$ with the emergence of the broad band in the 326$330 \mathrm{~cm}^{-1}$ range.

\subsection{Sulfidation of dried and calcined Co oxidic precursors supported on alumina}

Dried oxidic cobalt supported on alumina has been first characterized by XRD, XAS and Raman spectroscopies (Figures S10-S12). The XRD pattern is similar to the one of the alumina support. Only a linear combination fitting of XAS allows us to determine the composition of cobalt oxidic phases dispersed at the surface of the support as a mixture of $\mathrm{CoAl}_{2} \mathrm{O}_{4}$, CoAl-based Layered Double Hydroxide $(\mathrm{LDH})$ and $\mathrm{Co}\left(\mathrm{H}_{2} \mathrm{O}\right)_{6}{ }^{2+}$ oxidic species [48]. The lack of lines characteristic of $\mathrm{CoAl}_{2} \mathrm{O}_{4}$ and CoAl-based LDH both in Raman and XRD suggests a nanometric character of those phases dispersed on the support.

The monitoring of the sulfidation of the dried $\mathrm{Co} / \mathrm{Al}_{2} \mathrm{O}_{3}$ sample by Quick-XAS is presented in Figure 3 . The transformation of the oxidic species towards sulfided ones is characterized by the progressive decrease of the intense white line at $7726.5 \mathrm{eV}$ and continuous shift of the position of the rising edge from 7718 to $7715 \mathrm{eV}$ (inset of Figure 3). We can estimate that the complete vanishing of the white line occurs around $200^{\circ} \mathrm{C}$. Above this temperature, the shape of spectra is characteristic of sulfide cobalt species with the emergence of two characteristic spectra in Figure 3: the cyan and the red ones. The shape of those spectra is very similar to the shape of bulk $\operatorname{CoS}_{2}$ and $\mathrm{Co}_{9} \mathrm{~S}_{8}$ reported in Figures S2 and S5, respectively. The PCA analysis (Figure S13) carried out on this data set reveals that 3 components are necessary to explain most of the variance of the data evolution. The spectra of those components isolated by MCR-ALS are presented in Figure 4 . Figure S14 reports the $R_{f}$ factors calculated for each spectrum of the data set and compares it to the Lack Of Fit (LOF) of the MCR-ALS solution which is equal to $0.37 \%$ whereas Figure S15 displays some characteristic experimental spectra recorded during the sulfidation together with their rebuilt spectra and corresponding residual spectra. Reasonable LOF value and $R_{f}$ factors characterize the solution provided by MCR-ALS for the data set. The first species is identified as the pristine oxidic mixture of phases supported on alumina (Figure $4(\mathrm{a})$ ). Due to probable correlated variation of the concentrations of the different oxidic species dispersed at the surface of alumina upon sulfidation, $\mathrm{COAl}_{2} \mathrm{O}_{4}, \mathrm{CoAl}$-based $\mathrm{LDH}$ and $\mathrm{Co}\left(\mathrm{H}_{2} \mathrm{O}_{6}\right)^{2+}$ species cannot be isolated by the multivariate analysis and are labelled hereafter $\mathrm{CoO}_{x}$. This failure for isolating the different oxidic components is responsible to the increase of $R_{f}$ factors (Figure S14 (b)) at the onset of sulfidation (i.e. spectra in $\boldsymbol{D}$ with index $<100$ as shown in Figure S14 (a)) where the proportion of the oxidic species is greater than $50 \%$ in the mixture. Noteworthy, despite this increase, the $R_{f}$ factors still keep satisfactory values, which do not exceed $1.2 \%$. Two different sulfide species are also isolated, Sulfide 1 and Sulfide 2 (Figure 4). Those species are 
identified as being $\mathrm{CoS}_{2}$ and $\mathrm{Co}_{9} \mathrm{~S}_{8}$, respectively, first by comparison of their XANES spectra with those of bulk cobalt sulfide phases previously discussed and second through the results of EXAFS fitting (Figure S16 and Table 1). For Sulfide 1, although a slight shortening of distances in the first coordination Co-S shell (-0.06 $\AA$ ) and Co-Co shell (-0.10 $\AA$ ) is noted compared to crystalline $\mathrm{CoS}_{2}$ [44], the shape of the first FT contribution for this species is symmetric with no shoulder on the right side which could be ascribed to the formation of $\mathrm{Co}_{9} \mathrm{~S}_{8}[45,47]$ or $\operatorname{CoS}[45,49]$ associated with the Co-Co or Co-S contributions around 2.5-2.6 ̊ due to edge sharing tetrahedrons or square pyramids in these structures. Although the accuracy in the coordination number for the second coordination shell of Sulfide 1 is very poor $(\mathrm{N}(\mathrm{Co}-\mathrm{Co})=12.1 \pm 4.4)$ due to a high correlation between Debye Waller factors and $\mathrm{N}$, and, a probably highly disordered structure associated to the nanometric size of crystallites, the error bar reported for the first coordination shell (5.9 \pm 0.2 sulfur atoms) is small and allows us to conclude to the formation of cobalt with octahedral symmetry. Then the similarity of the XANES spectrum with the one of bulk $\mathrm{CoS}_{2}$ together with this octahedral site for cobalt gives reliable hints to identify Sulfide1 as $\operatorname{CoS}_{2}$. The EXAFS spectrum of Sulfide 2 is satisfactorily fitted with parameters fully in agreement with the structure of $\mathrm{Co}_{9} \mathrm{~S}_{8}$ [47]. Additionally, the Raman spectrum recorded at $400^{\circ} \mathrm{C}$ for Sulfide 2 supported on alumina displays lines at similar positions than those reported for bulk $\mathrm{Co}_{9} \mathrm{~S}_{8}$ (Figure S17), confirming its formation.

The evolution of concentration profiles of those three species as a function of the temperature is displayed in Figure 5, together with the Mass Spectrometry (MS) signals associated to $\mathrm{H}_{2} \mathrm{~S}(\mathrm{~m} / \mathrm{Z}=32$ ) and $\mathrm{H}_{2}(\mathrm{~m} / \mathrm{Z}=2)$ measured at the cell outlet. The oxidic species are first transformed into $\mathrm{CoS}_{2}$ species, the transformation being complete at $200^{\circ} \mathrm{C}$. The supported $\operatorname{CoS}_{2}$ species are stable in the $200-228^{\circ} \mathrm{C}$ temperature range before being transformed abruptly into $\mathrm{Co}_{9} \mathrm{~S}_{8}$. The conversion of $\mathrm{CoS}_{2}$ into $\mathrm{Co}_{9} \mathrm{~S}_{8}$ reaches about $80 \%$ at $270^{\circ} \mathrm{C}$ and is complete after $30 \mathrm{~min}$ of isothermal treatment at $400^{\circ} \mathrm{C}$. The abrupt conversion of $\mathrm{CoS}_{2}$ into $\mathrm{Co}_{9} \mathrm{~S}_{8}$ is accompanied by a MS signal corresponding to $\mathrm{H}_{2}$ consumption and a one corresponding to $\mathrm{H}_{2} \mathrm{~S}$ release. It is noteworthy that the abrupt transition revealed by the MCR-ALS analysis around $235^{\circ} \mathrm{C}$ can be also directly seen from the experimental data with the plot of the position of the rising edge, $\mathrm{E}_{1 / 2}$ corresponding to $50 \%$ level of the normalized absorbance as a function of temperature (inset Figure 3). $E_{1 / 2}$ moves abruptly from 7715.3 to 7714.7 $\mathrm{eV}$ around $235^{\circ} \mathrm{C}$ in agreement with the change of the formal cobalt oxidation state from +2 for $\mathrm{CoS}_{2}$ to +1.77 for $\mathrm{Co}_{9} \mathrm{~S}_{8}$.

The calcination at $450^{\circ} \mathrm{C}$ of the dried oxidic precursor under synthetic air leads to the dispersion at the surface of alumina of a mixture of $\mathrm{CO}_{3} \mathrm{O}_{4}, \mathrm{CoAl}_{2} \mathrm{O}_{4}, \mathrm{CoAl}$-based $\mathrm{LDH}$ phases and $\mathrm{Co}\left(\mathrm{H}_{2} \mathrm{O}\right)_{6}{ }^{2+}$ species [48] (Figures S10-S12). Besides the linear combinations using those references for rebuilding the RT XANES spectrum of the calcined $\mathrm{Co} / \mathrm{Al}_{2} \mathrm{O}_{3}$ sample, Raman spectroscopy confirms the formation of $\mathrm{Co}_{3} \mathrm{O}_{4}$ (Figure S12) whereas XRD evidences that those phases keep a nanometric size since no peaks other than those related to the support are observed.

The monitoring of the sulfidation by quick-EXAFS of the calcined $\mathrm{Co} / \mathrm{Al}_{2} \mathrm{O}_{3}$ sample is presented in Figure S18. Still 3 components are necessary for explaining the variance of the data set with LOF = $0.48 \%$. Contrarily to the dried precursor, the calcined one is not fully sulfided at the end of the treatment: $\approx 6 \%$ of irreducible oxide is observed even after $30 \mathrm{~min}$ of isothermal treatment at $400^{\circ} \mathrm{C}$. As for the dried $\mathrm{Co} / \mathrm{Al}_{2} \mathrm{O}_{3}$ sample, the sulfidation of calcined $\mathrm{Co} / \mathrm{Al}_{2} \mathrm{O}_{3}$ is still described by the formation of $\mathrm{CoS}_{2}$ and $\mathrm{Co}_{9} \mathrm{~S}_{8}$ but with incomplete conversion of oxidic species into $\mathrm{CoS}_{2}(\approx 55 \%$ at $140^{\circ} \mathrm{C}$ ) as previously observed (Figure 5 ) and concomitant formation of $\mathrm{Cog}_{9} \mathrm{~S}_{8}(\approx 25 \%$ ) between $25-$ $140^{\circ} \mathrm{C}$. The acceleration of the conversion of $\mathrm{CoS}_{2}$ into $\mathrm{Co}_{9} \mathrm{~S}_{8}$ occurs above $140^{\circ} \mathrm{C}$ with a transformation rate of $0.4 \% /{ }^{\circ} \mathrm{C}$ up to $240^{\circ} \mathrm{C}$ and a much slower conversion above $240^{\circ} \mathrm{C}\left(\approx 0.09 \% /{ }^{\circ} \mathrm{C}\right)$. 
At the end of $30 \mathrm{~min}$ of isothermal treatment at $400^{\circ} \mathrm{C}$, the composition is $80.5 \pm 0.3 \%$ of $\mathrm{Co}_{9} \mathrm{~S}_{8}, 13.9$ $\pm 0.3 \%$ of $\mathrm{CoS}_{2}$ and $5.6 \pm 0.1 \%$ of oxidic species $\left(R_{f}=0.35 \%\right)$.

\subsection{Sulfidation of dried and calcined Co oxidic precursors supported on silica}

The speciation of oxidic species on silica is different to the one described on alumina. On the one hand, silica being not prone to be lixiviated by the solution used during the impregnation and maturation stages contrarily to alumina [50], no oxidic precursor involving $\mathrm{Si}$ is formed. The dried oxidic precursor supported on silica is described as hydrated $\mathrm{Co}^{2+}$ species dispersed the surface of silica as determined by XAS (Figures S19-S20). On the other hand, due to the lower dispersing ability of silica compared to that of alumina, crystalline phases on the calcined catalyst, mainly composed of $\mathrm{CO}_{3} \mathrm{O}_{4}$, have been evidenced by XRD, Raman and XAS (Figures S20-S22). The average crystallite size deduced from the Scherrer's analysis of the well-defined reflections peaks of $\mathrm{Co}_{3} \mathrm{O}_{4}$ is $16 \mathrm{~nm}$.

Figures S23 and S24 report the monitoring of sulfidation for both samples and the related MCR-ALS solutions characterized by good LOF values similar to those obtained for the alumina support. Again $\mathrm{CoS}_{2}$ and $\mathrm{Co}_{9} \mathrm{~S}_{8}$ are the two sulfidic species formed upon sulfidation. Irrespective of the sample supported on silica, the transformation of $\mathrm{CoS}_{2}$ in $\mathrm{Co}_{9} \mathrm{~S}_{8}$ occurs around $200^{\circ} \mathrm{C}$ with an abrupt transformation rate between 200 and $210^{\circ} \mathrm{C}\left(3 \% /{ }^{\circ} \mathrm{C}\right.$ and $5 \% /{ }^{\circ} \mathrm{C}$ for the dried and calcined $\mathrm{Co} / \mathrm{SiO}_{2}$, respectively) and then more slowly at higher temperature. For both samples, sulfidation is complete but a few percentage of $\mathrm{CoS}_{2}$ is still present (10-15\%) after the $30 \mathrm{~min}$ of isothermal treatment at $400^{\circ} \mathrm{C}$. Contrarily to the calcined $\mathrm{Co} / \mathrm{Al}_{2} \mathrm{O}_{3}$ sample, no refractive oxide against sulfidation is observed for the calcined $\mathrm{Co} / \mathrm{SiO}_{2}$ sample. Starting from large $\mathrm{Co}_{3} \mathrm{O}_{4}$ crystallites $(16 \mathrm{~nm})$ supported on silica, the sulfidation of calcined $\mathrm{Co} / \mathrm{SiO}_{2}$ sample resulted in the formation of large $\mathrm{CO}_{9} \mathrm{~S}_{8}$ crystallites detectable by XRD (Figure S25). The average crystallite size determined by the Scherrer's formula is $14 \mathrm{~nm}$.

\subsection{Phase speciation after cooling down supported sulfidic cobalt supported species}

The measurements of the cooling down of the different supported samples under $\mathrm{H}_{2} \mathrm{~S} / \mathrm{H}_{2}$ surprisingly reported a partial re-sulfidation of $\mathrm{Co}_{9} \mathrm{~S}_{8}$ towards $\mathrm{CoS}_{2}$ when the temperature decreased. Namely, as shown in Figure $6(\mathrm{a})$, a modification of the shape of the XANES spectra is observed for the sulfided dried $\mathrm{Co} / \mathrm{Al}_{2} \mathrm{O}_{3}$ sample when the temperature is decreased from $400^{\circ} \mathrm{C}$ to $30^{\circ} \mathrm{C}$. Actually the composition at $30^{\circ} \mathrm{C}$ determined by MCR-ALS is: $46.0 \pm 1.1 \%$ of $\mathrm{Co}_{9} \mathrm{~S}_{8}$ and $54.0 \pm 1.1 \%$ of $\mathrm{CoS}_{2}$ (Figure 6 (b)). This transition of $\mathrm{Co}_{9} \mathrm{~S}_{8}$ towards $\mathrm{CoS}_{2}$ is confirmed by the Raman analysis of the sample measured at RT (Figure S26). Indeed, the main Raman line for this sample is located at $395 \mathrm{~cm}^{-1}$ which is at an intermediate position between the ones of $\operatorname{CoS}_{2}\left(390 \mathrm{~cm}^{-1}\right)$ and $\mathrm{Co}_{9} \mathrm{~S}_{8}\left(400 \mathrm{~cm}^{-1}\right)$ when both are measured at RT under $\mathrm{H}_{2} \mathrm{~S}_{/} \mathrm{H}_{2}$ atmosphere (Figure 1). Figure 7 reports the evolution of $\mathrm{Co}_{9} \mathrm{~S}_{8}$ and $\mathrm{CoS}_{2}$ percentages determined by MCR-ALS analysis of the XAS data recorded under $\mathrm{H}_{2} \mathrm{~S} / \mathrm{H}_{2}$ atmosphere when the cell temperature is decreased after sulfidation from 400 to $30^{\circ} \mathrm{C}$ (LOF $=0.64$ $\%$ ). A slow transformation occurs between 400 and $200^{\circ} \mathrm{C}$ with a conversion rate of $0.05 \% /{ }^{\circ} \mathrm{C}$ which clearly accelerates below $200^{\circ} \mathrm{C}$ for reaching a mixture of $50 \%$ of both sulfides at $92^{\circ} \mathrm{C}$. Below $100^{\circ} \mathrm{C}$, a nearly steady state in the reverse conversion of $\mathrm{Co}_{9} \mathrm{~S}_{8}$ into $\mathrm{CoS}_{2}$ seems to be reached. The sulfiding atmosphere used for decreasing the temperature from $400^{\circ} \mathrm{C}$ to RT is responsible for the reversible transition of $\mathrm{Co}_{9} \mathrm{~S}_{8}$ to $\mathrm{CoS}_{2}$, as it corresponds to a transition from a sulfide-poor species ( $\mathrm{S} / \mathrm{Co}=0.89$ ) toward a richer one $(\mathrm{S} / \mathrm{Co}=2)$. For example, for the dried $\mathrm{Co} / \mathrm{Al}_{2} \mathrm{O}_{3}$, the conversion of $\mathrm{Co}_{9} \mathrm{~S}_{8}$ into $54 \%$ of $\mathrm{CoS}_{2}$ corresponds to an uptake of 0.5 sulfur per cobalt atoms. We verified that no formation of 
$\mathrm{CoS}_{2}$ was observed under cooling down of the cell under argon atmosphere from 400 to $40^{\circ} \mathrm{C}$ (Figure S27).

Similar behaviours after cooling under sulfiding atmosphere were evidenced for the supported cobalt sulfides prepared herein, regardless the support, as soon as the phases do not display a long range order which could be characterized by XRD. Figure 8 compares the composition of the different samples measured at high temperatures, labelled herein $\mathrm{HT}\left(450\right.$ or $\left.400^{\circ} \mathrm{C}\right)$, and the ones determined after sample cooling at RT, labelled RT back. When $68 \mathrm{~nm}$-large bulk $\mathrm{Co}_{9} \mathrm{~S}_{8}$ or $16 \mathrm{~nm}$-large supported crystallites of $\mathrm{Co}_{9} \mathrm{~S}_{8}$ on silica (calc-Co/ $\mathrm{SiO}_{2}$ ) were prepared, no change of the composition was observed, whereas for the other supported samples, prepared from nanometric sized oxidic species and characterized by nanometric sized sulfidic species, a reverse transition towards $\mathrm{CoS}_{2}$ formation is observed. This finding emphasizes the highest reactivity of small particles towards the $\mathrm{H}_{2} \mathrm{~S}$ gas phase compared to the large ones inducing the reversible transformation of $\mathrm{Co}_{9} \mathrm{~S}_{8}$ towards the formation of $\mathrm{CoS}_{2}$ when the cell is cooled down to RT.

\subsection{Quantification of the CoMoS active species formed upon sulfidation of the calcined trimerie trimetallic $\mathrm{CoNiMo} / \mathrm{Al}_{2} \mathrm{O}_{3}$ catalyst}

The in-depth characterization carried out in this paper on the sulfidation of supported monometallic cobalt oxidic species has been motivated also by our interest to use those results to better characterize cobalt sulfidic species formed on a HDS catalyst. Our motivation is methodological in order to evaluate the use of quick-EXAFS sulfidation monitoring combined with MCR-ALS analysis to determine the relative percentage of the CoMoS HDS active species among the cobalt phases dispersed on alumina during and after activation. It is noteworthy that the rate of cobalt promotion is among many other descriptors a well-known parameter in the literature to be correlated with model molecules HDS catalyst activity [51, 52]. This information can be derived from XPS measurements [30,53] or from IR measurements of probe-molecule adsorption [54]. Irrespective of the techniques used for the evaluation of the amount of Co-promoted sites, they are always carried out after cooling down of activated catalysts, often under sulfiding atmospheres [53, 54]. Taking into account the afore presented results on the behaviour of supported monometallic $\mathrm{Co}_{9} \mathrm{~S}_{8}$ species during cooling for which a reverse solid-gas reaction under sulfiding atmosphere converts $\mathrm{Co}_{9} \mathrm{~S}_{8}$ into $\mathrm{CoS}_{2}$, the question of the stability of the CoMoS active phase is relevant to be addressed.

We choose for this proof-of-concept analysis a relatively conventional calcined catalyst prepared from ammonium heptamolybdate and cobalt nitrate. In order to have a composition of oxidic cobalt species closely related to the ones studied herein for the monometallic species, we selected a composition for which no $\mathrm{CoMoO}_{4}$ species was detected in the pristine oxidic precursor $[55,56]$. In the preparation conditions and loading used herein bimetallic CoMo calcined catalysts leading to the formation of $\mathrm{CoMoO}_{4}$ [56], the catalyst retained is a trimetallic calcined $\mathrm{CoNiMo} / \mathrm{Al}_{2} \mathrm{O}_{3}$ oxidic precursor for which the Raman spectrum (Figure S28) exhibited characteristic lines of bulk $\mathrm{MoO}_{3}$, in particular the most intense one at $819 \mathrm{~cm}^{-1}$, together with a broad and intense line centered at 950 $\mathrm{cm}^{-1}$, characteristic of polymolybdate species [57] but no lines related to the formation of $\mathrm{CoMoO}_{4}$ $[55,56]$. The linear combination fitting of the RT Co-K edge XANES spectrum of the pristine oxidic HDS catalyst precursor (Figure S29) reveals the dispersion of nanometer-sized $\mathrm{CoAl}_{2} \mathrm{O}_{4}(47.4 \pm 0.7 \%)$, $\mathrm{Co}\left(\mathrm{H}_{2} \mathrm{O}\right)_{6}{ }^{2+}(47.5 \pm 0.6 \%)$ and CoAl-based LDH $(5.1 \pm 1.0 \%)$ species [48]. The monitoring of the sulfidation of $\mathrm{Co}$ and Mo elements using the alternate recording of quick-XAS spectra at each edge is presented in Figure 9. The sulfidation of cobalt when added as promotor of molybdenum is faster than the ones observed for the monometallic cobalt catalyst (Figure S18) since it has been observed 
a more drastic reduction of the white line intensity as soon as the catalyst is in contact with $\mathrm{H}_{2} \mathrm{~S} / \mathrm{H}_{2}$ gaseous atmosphere at $30^{\circ} \mathrm{C}$ (Figure 9). Contrariwise, the evolution observed at the molybdenum $\mathrm{K}$ edge is in line with those already reported for $\mathrm{CoMo} / \mathrm{Al}_{2} \mathrm{O}_{3}$ and $\mathrm{Mo} / \mathrm{Al}_{2} \mathrm{O}_{3}$ catalysts $[36,39]$ with a progressive shift of the rising edge towards lower energy and vanishing of the pre-edge intensity characteristic of the exchange of oxygen ligands by sulfur ones. Due to the close vicinity of nickel $\mathrm{K}$ edge with the one of cobalt, the evolutions of nickel species have been also recorded (Figure S30) simultaneously to the ones of cobalt species. However, as the purpose of the paper is to illustrate the methodology for quantifying the CoMoS species during the sulfidation of HDS catalyst precursor, no further investigation has been done herein for the nickel promotor. Obviously for a complete structure-activity relationship understanding, the formation of NiMoS and monometallic $\mathrm{NiS}_{\mathrm{x}}$ species should be also considered.

The multivariate analysis of the evolution recorded at the Mo K edge under $\mathrm{H}_{2} \mathrm{~S} / \mathrm{H}_{2}$ for the CoNiMo oxidic precursor was performed considering 3 components, as determined by Principal Components Analysis (Figure S31). As detailed in Supplementary Information (Figure S32), the first component is related to the initial oxidic molybdenum-based species, the second one to an oxysulfide $\mathrm{MoO}_{x} \mathrm{~S}_{y}$ species whereas the third is identified as the $M_{0} S_{2}$ species. The $M_{0} S_{3}$ species, which is an intermediate usually described before the formation of $\operatorname{MoS}_{2}$ in the literature $[58,36,39,40]$, is surprisingly not isolated herein by MCR-ALS. We assume that this finding is related both to its low abundance (in proportion but also in number of spectra in the data set in which the species contributes) in the Mo K edge data set reported herein, and to the RT nucleation and growth of $\mathrm{MoS}_{2}$. When $\mathrm{MoS}_{3}$ was isolated by MCR-ALS $[36,39,40]$, its presence was detected over a large temperature range with onset of formation around $80^{\circ} \mathrm{C}$ and characterized by a maximum of abundance around $200-220^{\circ} \mathrm{C}$ corresponding to the onset of formation of $\mathrm{MoS}_{2}$. It is noteworthy that RT nucleation of $\mathrm{MoS}_{2}$ has been also observed in the literature by XPS [59], meaning that sulfidation kinetics are dependent of many parameters, in particular the hydration level of the oxidic precursors $[40,60]$. Strategies to isolate $\mathrm{MoS}_{3}$ during the sulfidation of this trimetallic oxidic precursor could then be proposed such as other sulfidation conditions (heating ramp, dehydration...) and/or other data recording in order to increase the number of spectra in which $\mathrm{MoS}_{3}$ is present in the mixture of species. For instance, by changing the edge jumping acquisition mode by a one with data only recorded at the Mo $\mathrm{K}$ edge over the full life span of activation multiplies by 4 the total number of spectra in the data set. But in that case, we lose the simultaneous recording of evolution of $\mathrm{Co}$ and $\mathrm{Mo}$ and the unambiguous comparison of fate of both elements upon sulfidation, as we will discuss later (vide infra).

At the Co K edge, the variance evaluation by PCA of the only data set composed of spectra recorded upon sulfidation of the CoNiMo precursor reveals 3 components (Figure S33). However, the minimization carried out on the basis of 3 components does not allow to properly isolate the pure chemical species involved during sulfidation, as discussed in Supplementary Information (Figure S34). In particular, the intermediate component extracted considering a solution with 3 components still presents a reminiscence of the white line characteristic of the oxide species. This is strong evidence that this component is not a pure species but a mixture of the oxidic species and of a sulfide one. Furthermore, the concentration of the third component is equal to $100 \%$ at $400^{\circ} \mathrm{C}$ which is not consistent with the formation of a mixture of $\mathrm{Co}_{9} \mathrm{~S}_{8}$ and $\mathrm{CoMoS}$ species reported in the literature [3, $30,39,45,51,53]$. As aforementioned, the species composing the pristine oxidic cobalt precursor in the trimetallic HDS catalyst are similar to those dispersed on the dried $\mathrm{Co} / \mathrm{Al}_{2} \mathrm{O}_{3}$ sample. Consequently, their evolution upon sulfidation should be related to the formation of $\operatorname{CoS}_{2}$ and $\mathrm{Co}_{9} \mathrm{~S}_{8}$ 
supported species, together with the expected formation of the active CoMoS species. The number of components which should be highlighted by the PCA analysis of the data recorded for the CoNiMo oxidic precursor should be therefore 4 with the 3 different sulfide species, $\mathrm{CoS}_{2}, \mathrm{Co}_{9} \mathrm{~S}_{8}$ and $\mathrm{CoMoS}_{\text {, }}$ and the initial cobalt oxidic species. The failure of detection of 4 components by PCA of the evolving data of CoNiMo oxidic precursor upon $\mathrm{H}_{2} \mathrm{~S} / \mathrm{H}_{2}$ exposure reveals a rank deficiency of the data, an issue which can occur when large similarity among species spectra or co-evolving concentration profiles exist [61]. The so-called column-wise augmented (CWA) data strategy consisting in adding to the data presenting rank deficiency an additional data set sharing some components with the former ones is powerful to break rank-deficiency and separate the three sulfide cobalt-based species. For this purpose, the CoNiMo oxidic precursor data recorded upon sulfidation were added to the one recorded for the dried $\mathrm{Co} / \mathrm{Al}_{2} \mathrm{O}_{3}$ sample for $\mathrm{T}>200^{\circ} \mathrm{C}$ (Figure 3), i.e. a data set containing only the mixture of $\mathrm{CoS}_{2}$ and $\mathrm{Co}_{9} \mathrm{~S}_{8}$ supported species. In that case, the PCA analysis of the CWA data set, which is presented on Figure S35, is consistent with the use of 4 components for explaining its variance. The CWA data set is further treated with the additional constraints that the oxidic species and the CoMoS species do not contribute to the concentration matrix for the data related to the dried $\mathrm{Co} / \mathrm{Al}_{2} \mathrm{O}_{3}$ sample. The results using this approach are presented in Figures $\mathrm{S} 36$ and $\mathrm{S} 37$. At the Co $\mathrm{K}$ edge, the $1^{\text {st }}$ component is related to the pristine cobalt oxidic species whereas the shape of the XANES spectra of the three other components is characteristic of three sulfide-based species (Figure S37). The EXAFS spectra extracted from the XAS data isolated by CWA-MCR analysis are presented in Figure 10. The spectra of the $3^{\text {rd }}$ (Figure 10 (b) and $4^{\text {th }}$ (Figure 10 (c)) components are compared to the experimental spectra of $\mathrm{CoS}_{2}$ and $\mathrm{Co}_{9} \mathrm{~S}_{8}$ species obtained during the sulfidation of the dried $\mathrm{Co} / \mathrm{Al}_{2} \mathrm{O}_{3}$ sample recorded in temperature or at $\mathrm{RT}$ after cooling under the appropriate atmosphere for which no change of phase is observed as afore discussed. Therefore, the $2^{\text {nd }}$ component, for which its EXAFS spectrum is presented in Figure 10 (a), is assumed to be related to the active CoMoS phase. Noteworthy are the differences of EXAFS oscillation shape between the spectra characteristic of the monometallic species in Figure 10 (b) and (c), with a monotonous decrease in intensity of oscillations beyond $6 \AA^{-1}$, which corresponds to the maximum of the scattering amplitude of $S$ backscatters, and the spectrum of the $2^{\text {nd }}$ component (Figure $10(a)$ ) with a two-maxima behaviour, one around $6 \AA^{-1}$ for sulfur backscatters and a second one around $10 \AA^{-1}$. The second maximum is related to the contribution of molybdenum backscatters in agreement with the reported position of the maximum of backscattering amplitude for this element [62] and gives strong support to relate this species as the CoMoS active phase as discussed also in [51]. To validate this assignment, the EXAFS spectrum for this $2^{\text {nd }}$ component was simulated by a least square fitting procedure considering two contributions of neighbours: a first coordination shell of sulfur and a second coordination shell of molybdenum atoms. A satisfactory simulation reported in Figure S38 and Table 2 is obtained with distances for the Co-S (at $2.22 \AA$ ) and Co-Mo (at $2.84 \AA$ ) contributions in agreement with the description of the CoMoS active phase reported from density functional theory (DFT) calculations [63] or from EXAFS fitting $[45,64]$.

Figure 11 displays the MCR-ALS evolution profiles of the $\mathrm{CoO}_{x}, \mathrm{CoS}_{2}, \mathrm{Co}_{9} \mathrm{~S}_{8}$ and $\mathrm{CoMoS}$ species characterizing the sulfidation of the CoNiMo oxidic precursors. We observe for the concentration profiles of $\mathrm{CoMoS}$ and $\mathrm{Co}_{9} \mathrm{~S}_{8}$ a very close evolution upon temperature increase, which is consistent with the observed rank deficiency characterizing the data set of CoNiMo catalyst when minimized without considering the CWA approach. Finally, as Co and Mo K edge data for this catalyst were recorded alternately during the same experiment, both data sets share the same temperature dependence. Then for comparison purpose and further detailed discussion, the evolution profile of 
the species isolated at the Mo K edge is also plotted with the concentration profile of cobalt-based species in Figure 11.

\section{Discussion}

In this paper, the Raman spectrum of bulk $\operatorname{Cog}_{9} S_{8}$ with characteristic lines at $400 \mathrm{~cm}^{-1}$ and satellite at $336 \mathrm{~cm}^{-1}$ when measured at RT under $\mathrm{H}_{2} \mathrm{~S} / \mathrm{H}_{2}$ with $532 \mathrm{~nm}$ laser excitation was reported in agreement with the spectrum recently published by Wang et al. [17]. The slight shift of the lines to low wavenumber $\left(-4 \mathrm{~cm}^{-1}\right)$ between our results and the spectrum in [17] could be related to the atmosphere under which both spectra were collected, as evidenced herein when the atmosphere was changed from $\mathrm{H}_{2} \mathrm{~S} / \mathrm{H}_{2}$ to inert atmosphere (Figure $\mathrm{S} 8$ (b)). But the atmosphere dependence of the line position is not responsible for the inconsistency of published results in the abundant literature related to electrocatalysts because the lines used in those papers are shifted by several hundreds of $\mathrm{cm}^{-1}$ compared to our positions. The formation of $\mathrm{Co}_{9} \mathrm{~S}_{8}$ is concluded from the presence of a main line at 573 [23], 586 [20], 650 [19], 667 [21] or $685 \mathrm{~cm}^{-1}$ [22] to cite only a few of these papers. We ascribe that those lines arise from laser radiation damage, since we have experienced by ourselves the high sensitivity of bulk $\mathrm{Co}_{9} \mathrm{~S}_{8}$ under air when the laser power was increased. (Figure S39). Two lines are present at low laser nominal power (less than $6 \mathrm{~mW}$ ) at 400 and $278 \mathrm{~cm}^{-1}$ and stable for more than $12 \mathrm{~h}$ under air for recording of 14 spectra corresponding to the merge of 12 spectra each acquired for 10s. The line at $400 \mathrm{~cm}^{-1}$ is well in line with the one reported for $\mathrm{Cog}_{9} \mathrm{~S}_{8}$ under $\mathrm{H}_{2} \mathrm{~S} / \mathrm{H}_{2}$ (Figure 1) whereas the line at $278 \mathrm{~cm}^{-1}$ could be related to surface oxidation of $\mathrm{Cog}_{9} \mathrm{~S}_{8}$ crystallites. As soon as the laser power is increased above $6 \mathrm{~mW}$, a broad line at $335 \mathrm{~cm}^{-1}$, with additional lines at $473-475$ and $678-680 \mathrm{~cm}^{-1}$ with quite similar intensities at $16 \mathrm{~mW}$, replaced the former lines. Finally, above $25 \mathrm{~mW}$, the line at $335 \mathrm{~cm}^{-1}$ strongly decreases and the characteristic intense lines of $\mathrm{CO}_{3} \mathrm{O}_{4}$ appear at 475, 515, 612 and $681 \mathrm{~cm}^{-1}$. By comparison with the reported values in the previous papers with the ones observed upon increasing the laser power, we suggest that these lines are due to irradiation damages with the formation of oxysulfide and/or oxidic phases.

The sulfidation of cobalt oxidic species supported on alumina and silica displays common intermediate sulfidic species identified as $\operatorname{CoS}_{2}$ and $\operatorname{Co}_{9} S_{8}$. The monitoring of gaseous products by Mass Spectrometry allows us to propose as reaction for the formation of $\mathrm{Co}_{9} \mathrm{~S}_{8}$ :

$$
\mathrm{CoS}_{2}+10 \mathrm{H}_{2}->\mathrm{CO}_{9} \mathrm{~S}_{8}+10 \mathrm{H}_{2} \mathrm{~S}
$$

This transition is more abrupt when starting from the dried oxidic precursors than from the calcined ones. Irrespective of the samples, this transition occurs around $180-240^{\circ} \mathrm{C}$, which is a temperature close to the temperature at which bulk $\mathrm{CoS}_{2}$ starts to be transformed into bulk $\mathrm{Co}_{9} \mathrm{~S}_{8}$ (Figure 2). The abruptness of transition from a sulfur-rich phase, $\mathrm{CoS}_{2}$, towards a sulfur-poor phase, $\mathrm{Co}_{9} \mathrm{~S}_{8}$, is very similar to the one reported for dried $\mathrm{Ni}$ oxidic species supported on alumina [26], highlighting the similarity of behaviours for supported oxidic species with a low metal loading ( $2.1 \mathrm{wt} \%$ for $\mathrm{Ni}$ and 4.0 wt \% for (Co). The structural parameters reported from the MCR-ALS analysis of the XAS data sets recorded during sulfidation for the supported pyrite $\mathrm{MS}_{2}$ phase, $\mathrm{M}=\mathrm{Ni}$ or $\mathrm{Co}$, have a common feature which is a shortening of distances between the metal and sulfur in the first coordination shell and metal nearest neighbours compared to those reported for bulk pyrites. The shortening of both distances could be ascribed to a contraction of cubic cell parameters of about 2-3\%. Recent DFT calculations have shown that single sulfur and cobalt vacancies and double Co-S vacancies are easily formed in bulk cobalt pyrite [65]. In particular, the DFT calculation of the lattice parameter dependence on $\mathrm{S}$ vacancy concentration shows that a contraction of $3 \%$ can be associated with $2 \mathrm{~S}$ 
vacancies [66]. In order to confirm the presence of sulfur vacancies in the phase formed at $200^{\circ} \mathrm{C}$ upon sulfidation of dried $\mathrm{Co} / \mathrm{Al}_{2} \mathrm{O}_{3}$, this phase was analysed by XPS. The $200^{\circ} \mathrm{C}-\mathrm{Co} / \mathrm{Al}_{2} \mathrm{O}_{3}$ sample was prepared by stopping the sulfidation at $200^{\circ} \mathrm{C}$ and immediately decreasing the temperature up to RT under $\mathrm{H}_{2} \mathrm{~S} / \mathrm{H}_{2}$ atmosphere. The purge of the cell under argon was carried out at RT. Figure $\mathrm{S} 40$ reports the Co $2 p$ and $S 2 p$ XPS spectra for this as-prepared $200^{\circ} \mathrm{C}-\mathrm{Co} / \mathrm{Al}_{2} \mathrm{O}_{3}$ sample. The decomposition of the Co $2 p$ spectrum has been performed considering the metallic character of the pyrite which leads to introduce plasmonic and Auger peaks in the decomposition as reported in [67] and gives a main $2 \mathrm{p}_{3 / 2}$ contribution located at $778.1 \mathrm{eV}$, in agreement with the value reported for bulk $\mathrm{CoS}_{2}$ [68]. The S $2 p$ spectrum consists of two doublets with $S 2 p_{3 / 2}$ energies of $161.7 \mathrm{eV}$ and 164 $\mathrm{eV}$ together with a small contribution of sulfate ions at higher energies $(\approx 169 \mathrm{eV})$. The doublet located at $164\left(2 p_{3 / 2}\right)$ and $165.2 \mathrm{eV}\left(2 p_{1 / 2}\right)$ could be ascribed to elemental sulfur whereas the position of the $2 p_{3 / 2}$ at $161.7 \mathrm{eV}$ is different to the one reported for $\mathrm{S}_{2}{ }^{2-}$ for bulk $\operatorname{CoS}_{2}$ by $\approx-0.9 \mathrm{eV}$, which could be related to a slight band structure modification associated to vacancy formation as discussed in [65]. The chemical composition of the $200^{\circ} \mathrm{C}-\mathrm{Co} / \mathrm{Al}_{2} \mathrm{O}_{3}$ sample determined by XPS is $\mathrm{CoS}_{1.9}$ which is consistent with the formation of a defective $\mathrm{CoS}_{2}$ structure deduced from XAS analysis in agreement with DFT calculations.

A complete sulfidation of oxidic precursor is observed for most of the supported monometallic samples, except for the calcined oxidic precursors supported on alumina where about $6 \%$ of oxidic species is still remaining after $30 \mathrm{~min}$ of sulfidation at $400^{\circ} \mathrm{C} . \mathrm{CO}_{3} \mathrm{O}_{4}$ and $\mathrm{CoAl}_{2} \mathrm{O}_{4}$ species were both detected as composing the calcined $\mathrm{Co} / \mathrm{Al}_{2} \mathrm{O}_{3}$ sample but the full sulfidation of the calcined $\mathrm{Co} / \mathrm{SiO}_{2}$ sample mainly composed of $\mathrm{CO}_{3} \mathrm{O}_{4}$ crystallites is a strong indication that the remaining oxidic species on the sample supported on alumina must be ascribed to the well-known difficulty to sulfide spinellike cobalt aluminate [3]. Everything else being equal, in particular the heating ramp of $3^{\circ} \mathrm{C} / \mathrm{min}$ (Figure 8), dried samples give rise after $30 \mathrm{~min}$ of isothermal treatment at $400^{\circ} \mathrm{C}$ to the higher proportion of $\mathrm{Co}_{9} \mathrm{~S}_{8}(90 \%)$ still mixed with $\mathrm{CoS}_{2}$. It is noteworthy that increasing the ramp to 5 (Figures 3 and 5 ) or $10^{\circ} \mathrm{C} / \mathrm{min}$ (not shown) for the dried $\mathrm{Co} / \mathrm{Al}_{2} \mathrm{O}_{3}$ sample gives rise to complete sulfidation into $\mathrm{Co}_{9} \mathrm{~S}_{8}$. As discussed in the next section of this paper related to the sulfidation of the CoNiMo sample, the fine description of the monometallic cobalt species involved upon sulfidation will be important for unravelling the complexity of sulfidation of cobalt in presence of molybdenum.

Another striking result coming from the monitoring of species formed upon sulfidation of supported cobalt catalysts and subsequent cooling is the reactivity of the supported $\operatorname{Cog}_{9} S_{8}$ phase. When the temperature is decreased under $\mathrm{H}_{2} \mathrm{~S} / \mathrm{H}_{2}$ (Figure 7), the rich-sulfiding atmosphere is responsible for the new uptake of sulfur with respect to cobalt when the sample is back at RT. This uptake is higher for the samples presenting a high dispersion of $\mathrm{Co}_{9} \mathrm{~S}_{8}$, ie those supported on alumina or the one resulting from the sulfidation of dried $\mathrm{Co} / \mathrm{SiO}_{2}$. At the opposite, the composition of the bulk $\mathrm{Co}_{9} \mathrm{~S}_{8}$ and calcined $\mathrm{Co} / \mathrm{SiO}_{2}$ samples does not change upon cooling. As already mentioned, this is a strong indication that the dispersion of $\mathrm{Co}_{9} \mathrm{~S}_{8}$ plays a key role in the reverse $\mathrm{Co}_{9} \mathrm{~S}_{8} \rightarrow \mathrm{CoS}_{2}$ transition. It is noteworthy that the presence of the defective $\mathrm{CoS}_{2}$ in highly dispersed samples is well in line with the results obtained by Ledoux et al. [29] using solid state ${ }^{59} \mathrm{Co}$ NMR to determine cobalt speciation on silica. Their characterization evidenced four different cobalt sites after sulfidation with two of them corresponding to the regular octahedral and tetrahedral $\mathrm{Co}_{9} \mathrm{~S}_{8}$ sites found regardless the studied cobalt loading that ranged from 38.3 to $2.5 \mathrm{wt} \%$ and two additional sites corresponding to a distorted tetrahedral site and a distorted octahedral site, only observed for the lowest loadings. The distorted octahedral site which was surmised by Ledoux et al. to be related to the CoS phase [29] is ascribed, considering our results, to be the defective $\mathrm{CoS}_{2}$ which is reformed during cooling for 
dispersed species on silica and alumina. As Ledoux could not study alumina-supported catalysts under the NMR conditions they used, our study enlarges their conclusions to alumina support. Finally, similar $\mathrm{Co}_{9} \mathrm{~S}_{8} / \mathrm{CoS}_{2}$ reversibility has been also evidenced for silica and alumina supported Cobased catalysts by Dujardin [69] using low temperature CO adsorption followed by FTIR spectroscopy. Sulfidation of supported cobalt-based catalysts leads to a characteristic line at 2094 $\mathrm{cm}^{-1}$ for the alumina support [69, 70] and $2110 \mathrm{~cm}^{-1}$ for the silica one [69], which is characteristic of the interaction of $\mathrm{CO}$ with sulfide cobalt species. Upon further $\mathrm{H}_{2}$ treatment of the sulfided catalysts at $300^{\circ} \mathrm{C}$, the creation of sulfur vacancies in the sulfided species occurs by removing sulfur in the form of $\mathrm{H}_{2} \mathrm{~S}$, with a new line appearing at $2056 \mathrm{~cm}^{-1}$ on the alumina support and $2063 \mathrm{~cm}^{-1}$ on the silica one. This behaviour was ascribed by Dujardin to the transformation of a rich-sulfide cobaltbased phase into a species with lower sulfur content which was associated to $\mathrm{Co}_{9} \mathrm{~S}_{8}$. Irrespective of the assignation done by Dujardin et al. on the different lines, this study still highlights the high solidgas reactivity of the sulfided species formed by sulfidation towards defective ones in sulfur as the $\mathrm{CoS}_{2}$ species was described at the light of our results.

Thanks to the extensive study of Co-supported materials sulfidation, we report in this paper for the first time the in situ quantification of the CoMoS species on a CoNiMo supported HDS catalyst from the MCR-ALS analysis of its gas sulfidation XAS monitoring. It is noteworthy that due to the use of an element-selective technique such as XAS, the methodology used for this purpose is general and can be applied to any HDT catalysts containing cobalt as promotor, irrespective of its chemical composition. By introducing the $\mathrm{CoS}_{2}$ and $\mathrm{Co}_{9} \mathrm{~S}_{8}$ spectra systematically observed for Co-based monometallic catalysts, regardless of the support, through the data set augmentation method, the spectrum of a third cobalt based sulfide species has been isolated and its concentration evolution profile described. The assignment of this sulfide species to the CoMoS active phase has been obtained from its EXAFS analysis and reproduction of the beat pattern at $10 \AA^{-1}$ characteristic of the backscattering of the photoelectron by heavy Mo backscatters (Figure 10 and Figure S38). It is important to keep in mind that the Co K edge EXAFS fingerprint which is used for the CoMoS phase described in the literature is a purely local point of view analysis highlighting only the characteristic Co-S-Mo interaction. From the Co K edge EXAFS data fitting, no information related about the extent of the $\mathrm{MoS}_{2}$ slab promoted by Co can be obtained. This information is obtained indirectly by the Mo $\mathrm{K}$ edge XAS monitoring which provides the evidence of $\mathrm{MoS}_{2}$ formation or directly by HAADF-STEM analysis [71, 72]. The "Co-S-Mo" species, when Co is in interaction with Mo at the early stage of nucleation of $\mathrm{MoS}_{2}$ slabs involving a very few number of Mo atoms, displays an EXAFS signal similar to the CoMoS active species observed at $400^{\circ} \mathrm{C}$ when $\mathrm{MoS}_{2}$ is mainly formed, except with a higher Debye-Waller factor due to the increase of temperature.

Our results highlight for the calcined CoNiMo catalyst the competitive formation of $\mathrm{CoS}_{2}$ and $\mathrm{CoMoS}$ at the early stages of the sulfidation (Figure 11). At temperature higher than $150^{\circ} \mathrm{C}$ a clear conversion of $\mathrm{CoS}_{2}$ into $\mathrm{Co}_{9} \mathrm{~S}_{8}$ occurs leading at the end of heating $\left(400^{\circ} \mathrm{C}\right)$ to $45 \%$ of $\mathrm{Co}_{9} \mathrm{~S}_{8}$. The formation of "CoS-Mo" species starting at RT, in agreement with the onset of nucleation of $\mathrm{MoS}_{2}$, is fast between 30 and $100^{\circ} \mathrm{C}$ with $\approx 27 \%$ of CoMoS formed at $100^{\circ} \mathrm{C}$ and slows down with a quasi linear behaviour of $0.07 \% /{ }^{\circ} \mathrm{C}$ until to reach $400^{\circ} \mathrm{C}$. At this temperature, $\approx 49 \%$ of CoMoS is formed with a percentage which does not change during the 2 hours of isothermal treatment (Figure S41). As expected for a calcined catalyst, about $6 \%$ of Co species remains at the oxidic state probably associated to the formation of $\mathrm{CoAl}_{2} \mathrm{O}_{4}$ species. It is noteworthy that for a calcined CoMoP supported catalyst on alumina, the room temperature formation of CoMoS and $\mathrm{MoS}_{2}$ nuclei, described by TEM as nonorganized particles as soon as the sulfidation temperature is below $200^{\circ} \mathrm{C}$, has been also reported 
by ex situ Co 2p and Mo 3d XPS characterization done for samples sulfided at different temperatures $\left(25,100,200,300,350,400,500\right.$ and $\left.600^{\circ} \mathrm{C}\right)[3,59]$. The ex situ XPS characterization required to repeat the sulfidation process at the different temperatures in order to access to the Co and Mo speciation. Herein a single experiment, where sulfidation is alternately monitored at Co and Mo $\mathrm{K}$ edges, allows for accessing to the same information but with a temperature step of $6^{\circ} \mathrm{C}$ between each measure. It is interesting to note also that the concomitant presence of $\mathrm{CoS}_{2}$ and $\mathrm{Co}_{9} \mathrm{~S}_{8}$ species observed by XAS are not resolved by the ex situ XPS characterisation $[53,59]$. Due to the fact that we have demonstrated herein that a conversion of nano-sized $\mathrm{Co}_{9} \mathrm{~S}_{8}$ particles towards nano-sized $\mathrm{CoS}_{2}$ ones occurs when the temperature is decreased under sulfiding atmosphere and that both sulfides are characterized by a $2 p$ peak emission located at the same position $(778.1 \mathrm{eV})[68,59]$, their distinction by XPS is impossible and makes incomplete the cobalt speciation of monometallic species reported by the photoemission technique. For the CoNiMo catalyst studied herein, we verified that the linear combination of the XAS spectrum recorded after sulfidation and temperature decrease to RT under $\mathrm{H}_{2} \mathrm{~S} / \mathrm{H}_{2}$ atmosphere evidences that the percentage of CoMoS is not affected and remains at the level of $45 \pm 1 \%$, but the conversion of $\mathrm{Co}_{9} \mathrm{~S}_{8}$ into $\mathrm{CoS}_{2}$ still occurs with $32 \pm 1 \%$ of $\operatorname{CoS}_{2}$ and $20 \pm$ $1 \%$ of $\mathrm{Cog}_{9} \mathrm{~S}_{8}$ at RT (Figure 12). The invariance of amount of CoMoS species upon temperature decrease validates therefore the correlation observed between the catalyst activity for HDT reactions carried out in a temperature range close to the activation temperature $\left(300-400^{\circ} \mathrm{C}\right)$ and the amount determined by ex situ techniques such as XPS $[30,53]$ or by IR probe molecule adsorption, which requires to measure under liquid nitrogen temperature $[54,71]$.

\section{Conclusions}

In this paper, the formation of bulk $\mathrm{Co}_{9} \mathrm{~S}_{8}$ certified by its XRD pattern and Co $\mathrm{K}$ edge characterizations has been reported through the heating of bulk $\mathrm{CoS}_{2}$ phase under sulfiding atmosphere. This allows us to unambiguously report the Raman spectrum of the $\mathrm{Co}_{9} \mathrm{~S}_{8}$ phase in temperature and after cooling down at RT, which could be used further to identify $\mathrm{Co}_{9} \mathrm{~S}_{8}$ nanometric-sized phases studied as supported (electro)-catalysts.

The sulfidation pathways under $10 \% \mathrm{H}_{2} \mathrm{~S} / \mathrm{H}_{2}$ atmosphere of dried and calcined cobalt supported oxidic species on alumina and silica have been studied by Co $\mathrm{K}$ edge quick-XAS spectroscopy combined with multivariate analysis. These pathways share a common characteristic: first the cobalt oxidic species is transformed into nanometer-sized $\operatorname{CoS}_{2}$ particles before to be converted into nanometer-sized $\mathrm{Co}_{9} \mathrm{~S}_{8}$ particles. The nanometer character of the $\mathrm{Co}_{9} \mathrm{~S}_{8}$ particles is responsible of their high reactivity against $\mathrm{H}_{2} \mathrm{~S}$ when they are cooled down to RT with the partial (re)conversion into $\mathrm{CoS}_{2}$. The smaller the $\mathrm{Co}_{9} \mathrm{~S}_{8}$ nanoparticles the higher the amount of formed $\mathrm{CoS}_{2}$ after cooling.

Finally, for the first time, the in situ quantification of the CoMos active species formed upon sulfidation of a calcined cobalt promoted molybdenum-based HDS catalyst has been achieved using the so-called column-wise augmented strategy consisting in minimizing the data set composed of the monitoring of the sulfidation of the supported HDS catalyst and those collected during quick-XAS data monitoring of monometallic dried cobalt oxidic species supported on alumina where only a mixture of the supported $\mathrm{CoS}_{2}$ and $\mathrm{Co}_{9} \mathrm{~S}_{8}$ species is present. The conversion of $\mathrm{Co}_{9} \mathrm{~S}_{8}$ into $\mathrm{CoS}_{2}$ is still observed for the HDS catalyst when temperature is decreased under $\mathrm{H}_{2} \mathrm{~S} / \mathrm{H}_{2}$ atmosphere but this conversion does not change the CoMoS percentage between the end of the sulfidation at $400^{\circ} \mathrm{C}$ and RT. The method described herein is unique for reporting the cobalt speciation and could significantly contribute to establishing a relationship between active phase formation, catalysis genesis on one hand and catalytic activity on the other hand for cobalt promoted HDS catalysts. 


\section{Acknowledgements}

This work was supported by a public grant overseen by the French National Research Agency (ANR) as a part of the "Investissements d'Avenir" (ref: ANR-10-EQPX-45) provided for the building and operation of the ROCK beamline. The authors would like to thank SOLEIL for providing beamtime at the ROCK beamline and extend their appreciation to Philippe Lecour and Christèle Legens from IFP Energies Nouvelles for XPS measurements and spectra decomposition. 


\section{References}

[1] E. Cadot, M. Lacroix, M. Breysse, E. Arretz, J. Catal. 164 (1996) 490-492.

[2] V Mashkina, A V Mashkina, O P Krivoruchko, L N Khairulina Kinetics and Catalysis, 49 (2008) 103109.

[3] "Catalysis by Transition Metal Sulphides.From molecular theory to industrial applications. H. Toulhoat and P. Raybaud, Editors, Technip Edition, Paris, 2013.

[4] I. Alstrup, I. Chorkendorf, R. Candia, B. S. Clausen, H. Topsoe, J. Catal. 77 (1982) 397-409.

[5] H Topsøe, R Candia, N Y Topsøe, B S Clausen, Bull. Soc. Chim. Belges 93 (1984) 783-806.

[6] A S Bambal, V S Guggilla, E L Kugler, T H Gardner, D B Dadyburjor, Ind. Eng. Chem. Res 53 (2014) 5846-5857.

[7] Y. Liu, C. Xiao, M. Lyu, Y. Lin, W. Cai, P. Huang, W. Tong, Y. Zhou, Y. Xie, Angew. Chem. Ind. Ed. 54 (2015) 11231-11235.

[8] J. Zhang, X. Bai, T. Wang, W. Xiao, P. Xi, J. Wang, D. Gao, J. Wang, Nano-Micro Lett. 11 (2019) 113.

[9] H. Zhang, Y. Li, T. Xu, J. Wang, Z. Huo, P. Wan, X. Sun, J. Mater. Chem. A 3 (2015) 15020-15022.

[10] N. Kornienko, J. Resasco, N. Becknell, C. M. Jiang, Y. S. Liu et al. J. Am. Chem. Soc. 137 (2015) 7448-7455.

[11] C. Su, J. Xiang, F. Wen, L. Song, C. Mu, D. Xu, C. Hao, Z. Liu, Electrochimica Acta 212 (2016) $941-$ 949.

[12] J. Zhang, W. Xiao, P. Xi. S. Xi, Y. Du, D. Gao, J. Ding, ACS Energy Lett. 2 (2017) 1022-1028.

[13] Q. Shi, C. Zhu, D. Du, Y. Lin, Chem. Soc. Rev. 48 (2019) 3181-3192.

[14] P. J Masset, R. A. Guidotti J. Power Sources 178 (2008) 456-466.

[15] C. J. Chen, P. T. Chen, M. Basu, K. C. Yang, Y. R. Lu, C. L. Dong, C. G. Ma, C. C. Shen, S. F. Hu, R. S. Liu J. Mater. Chem. A 3 (2015) 23466-23476.

[16] S. G. Lyapin, A. N . Utyuzh, A. E. Petrova, A. P. Novikov, T. A. Lograsso, Z. M. Stichov, J. Physics Condensed Matter 26 (2014) 396001.

[17] J. Wang, H. Liu, W. Wang, Q. Sun, X. Wang, X. Zhao, H. Hu, M. Wu, Carbon 144 (2019) 259-268.

[18] L. Chen, W. Yang, X. Li, L. Han and M. Wei, J. Mater. Chem. A 7 (2019) 10331-10337.

[19] L. Yang, H. Li, S. Zhang, F. Yao, J. Lv, S. Xu, J. Alloys and Compounds 768 (2018) 485-494.

[20] T. M. Mashikhwa, M. J. Madito, A. Bello, J. Lekitima, N. Marryala, RSC Advances 7 (2017) 2023120240.

[21] Q. Gao, Z. Shi, K. Xue, Z. Ye, Z. Hong, X. Yu, M. Zhi, Nanotechnology 29 (2018) 215601.

[22] L. L. Feng, G. D. Li, Y. Liu, Y. Wu, H. Chen, Y. Wanf, Y. C. Zou, D. Wang, X. Zou, ACS applied Materials \& Interfaces, 7 (2015) 980-988.

[23] P. F. Yin, L. L. Sun, Y. L. Gao, S. Y. Wang, Bull. Mater. Sci. 31 (2008) 593-596.

[24] N. Kumar, N. Raman, A. Sundaresan, Z. Anorg. Allg. Chem. 640 (2014) 1069-1074.

[25] D. M. Pasquariello, R. Kershaw, J. D. Passaretti, K. Dwight, A. Wold, Inorg. Chem. 23 (1984) $872-$ 874.

[26] A. Rochet, A. Ribeiro Passos, C. Legens, V. Briois, Catal. Struct. React. 3 (2017) 33-42.

[27] A. de Juan, J. Jaumot, and R. Tauler, Anal. Methods 6 (2014) 4964-4976.

[28] B. Scheffer, J. C. M. de Jonge, P. Arnoldy, J. A. Moulijn Bull. Soc. Chim. Belg. 93 (1984) 751-762.

[29] M. J. Ledoux, O. Michaux, G. Agostini, P. Panissod, J. Catal. 96 (1985) 189-201.

[30] A. D. Gandubert, C. Legens, D. Guillaume, S. Rebours, E. Payen, Oil \& Gas Science and Technology 62 (2007) 79-89.

[31] V. Briois, C. La Fontaine, S. Belin, L. Barthe, T. Moreno, V. Pinty, A. Carcy, R. Girardot, E. Fonda, J. Phys. Conf. Ser. 712 (2016) 12149. 
[32] C. La Fontaine, F. Villain, V. Briois, X. Sécordel, A. Yoboué, A. Berrier, S. Cristol, Coupled XASRaman Operando analysis of $\mathrm{TiO}_{2}$ supported oxomolybdate catalysts in methanol conversion. I. Harrick Scientific Products (Ed.), Applications Note n91201. (2010).

[33] C. La Fontaine, L. Barthe, A. Rochet, V. Briois, Catal. Today 205 (2013) 148-158.

[34] E. Fonda, A. Rochet, M. Ribbens, L. Barthe, S. Belin, V. Briois, J. Synchrotron Radiat. 19 (2012) 417-424.

[35] M. C. Biesinger, B. P. Payne, A. P. Grosvenor, L. W. M. Lau, A. R . Gerson, R. St C. Smart, Applied Surface Science 257 (2011) 2717-2730.

[36] C. Lesage, E. Devers, C. Legens, G. Fernandes, O. Roudenko, V. Briois, Catal. Today 336 (2019) 6373.

[37] C. Ruckebusch, L. Blanchet, Anal. Chim. Acta 765 (2013) 28-36.

[38] H. R. Keller, D. L Massart, Chemom. Intel. Lab. Syst. 12 (1992) 209-224.

[39] A. Rochet, B. Baubet, V. Moizan, C. Pichon, V. Briois, Comptes Rendus Chim. 19 (2016) 13371351.

[40] A. Rochet, B. Baubet, V. Moizan, E. Devers, A. Hugon, C. Pichon, E. Payen, V. Briois, J. Phys. Chem. C 121 (2017) 18544-18556.

[41] J. Jaumot, R. Gargallo, A. de Juan, R. Tauler, Chemometr. Intell. Lab. Syst. 76 (2005) 101-110.

[42] B. Ravel, M. Newville, J. Synchrotron Radiat. 12 (2005) 537-541.

[43] W. Jauch, M. Reehuis, H. J. Bleif, F. Kubanek, P. Pattison, Phys. Rev. B 64 (2001) 052102-1052102-3.

[44] E. Nowack, D. Schwarzenbach, T. Hahn, Acta Crystallogr. B Struct. Sci. 47 (1991) 650-659.

[45] S. M. A. M. Bouwens, J. A.R. van Veen, D. C. Koningsberger, V. H. J. de Beer, R. Prins, J. Phys. Chem. 95 (1991) 123-134.

[46] S. M. A. M. Bouwens, D. C. Koningsberger, V. H. J. de Beer, R. Prins, Catal. Letters 1 (1988) 55-60.

[47] S. Geller, Acta Cryst. 15 (1962) 1195-1198.

[48] A. R. Passos, L. Martins, S. H. Pulcinelli, C. V. Santilli, V. Briois, ChemCatChem 9 (2017) 39183929.

[49] N. Alsén, Geol. Foereningan i Stock. Foerhandlingar 47 (1925) 19-72.

[50] J. B. d'Espinose de la Caillerie, M. Kermarec, O. Clause, J. Am. Chem. Soc. 117 (1995) 11471-11481.

[51] L. van Haandel, G. M. Bremmer, E. J. M. Hensen, Th. Weber, J. Catal. 342 (2016) 27-39.

[52] B. Guichard, M. Roy-Auberger, E. Devers, C. Legens, P. Raybaud, Catal. Today 130 (2008) 97-108.

[53] A. D. Gandubert E. Krebs, C. Legens, D. Costa, Catal. Today 130 (2008) 149-159.

[54] M. A. Lélias, J. van Gestel, F. Maugé, J. A. R. van Veen, Catal. Today 130 (2008) 109-116.

[55] E. Payen, M. C. Dhamelincourt, P. Dhamelincourt, J. Grimblot, J. P. Bonelle, App. Spectros. 36 (1982) 30-37.

[56] C. P. Cheng, G. L. Schrader, J. Catal. 60 (1979) 276-294.

[57] S. Kasztelan, J. Grimblot, J. P. Bonnelle, E. Payen, H. Toulhoat, Y. Jacquin, Appl. Catal. 7 (1983) 91-112.

[58] Th. Weber, J. C. Muijsers, J. H. M. C. van Wolput, C. P. J. Verhagen, J. W. Niemantsverdriet, J. Phys. Chem. 100 (1996) 14144-14150.

[59] A. D. Gandubert, C. Legens, D. Guillaume, E. Payen, Surf. Interface Anal. 38 (2006) 206-209.

[60] E. Le Guludec, L. Oliviero, J. P. Gilson, F. Maugé, M. Rebeilleau, V. De Grandi, S. A. van Donk, Catal. Sci. Technol. 5 (2015) 835-842.

[61] C. Ruckebush, A. De Juan, L. Duponchel, J. P. Huvenne, Chemometr. Intell. Lab. Syst. 80 (2006) 209-214. 
[62] S. P. Cramer, K. O. Hodgson, E. I. Stiefel, W. E. Newton, J. Am. Chem. Soc. 100 (1978) 2748-2461. [63] E. Krebs, A. Daudin, P. Raybaud, Oil\& Gas Science and Techn. 64 (2009) 707-718.

[64] D. Genuit, P. Afanasiev, M. Vrinat, J. Catal. 235 (2005) 302-317.

[65] S. Li, Y. N. Zhang, X. Niu, Phys. Chem. Chem. Phys. 20 (2018) 11649-11655.

[66] J. Zhang, W. Xiao, P. Xi, S. Xi, Y. Du, D. Gao, J. Ding ACS Energy Lett. 2 (2017) 1022-1028.

[67] C. Desjacques « Apports des méthodes photon-in/photon -out à la compréhension des systèmes catalytiques complexes » $\mathrm{PhD}$ thesis University of Lille 1 (2018).

[68] H. van der Heide, R. Hemmel, C. F. van Bruggen, C. Haas, J. Solid State Chem. 33 (1980) 17-25.

[69] C. Dujardin "Caractérisation de catalyseurs d'hydrotraitement par réactions modèles et spectroscopie infrarouge : apport à la compréhension du fonctionnement sur charge réelle. " PhD thesis, University of Caen (2002).

[70] A. Travert, C. Dujardin, F. Maugé, E. Veilly, S. Cristol, J.-F. Paul, E. Payen, J. Phys. Chem. B 110 (2006) 1291-1270.

[71] L. A. Zavala Sanchez "Supported transition metal disulfide catalysts for ultra-deep HDS: Coupling of IR spectroscopy and high resolution microscopy for a deeper insight into active sites. » PhD thesis, University of Caen Normandie (2019).

[72] M. Kulikova, A. Mozhaev, C. Lancelot, M. Marinova, P. Blanchard, E. Payen C. Lamonier, P. Nikulshin. Applied Catalysis B: Env. 224 (2018) 951-959. 


\begin{tabular}{|c|c|c|c|c|c|c|c|}
\hline & $\mathrm{N}$ & $R(\AA)$ & $\begin{array}{c}R(\AA ̊) \\
\text { from XRD }\end{array}$ & $\sigma^{2}\left(10^{-3} \AA^{2}\right)$ & $\begin{array}{l}\text { enot } \\
(\mathrm{eV})\end{array}$ & $R_{f}(\%)$ & $\chi_{\text {red }}^{2}$ \\
\hline \multicolumn{8}{|c|}{ Sulfide 1} \\
\hline Co-S & $5.9 \pm 0.2$ & $2.25 \pm 0.02$ & 2.31 & $8.1 \pm 0.6$ & \multirow{3}{*}{0.73} & \multirow{3}{*}{0.3} & \multirow{3}{*}{29522} \\
\hline Co-S & $7.2 \pm 1.6$ & $3.56 \pm 0.02$ & 3.545 & $23.4 \pm 7.6$ & & & \\
\hline Co-Co & $12.1 \pm 4.4$ & $3.79 \pm 0.03$ & 3.89 & $40.6 \pm 6.7$ & & & \\
\hline \multicolumn{8}{|c|}{ Sulfide 2} \\
\hline Co-S & $4.0 \pm 0.1$ & $2.21 \pm 0.01$ & 2.22 & $9.6 \pm 0.3$ & \multirow[b]{2}{*}{0.03} & \multirow[b]{2}{*}{0.09} & \multirow[b]{2}{*}{10089} \\
\hline Co-Co & $2.1 \pm 0.2$ & $2.56 \pm 0.03$ & 2.50 & $15.3 \pm 0.9$ & & & \\
\hline
\end{tabular}

Table 1: Structural parameters determined for Sulfide 1 and Sulfide 2 components isolated by MCRALS analysis of the data set recorded upon sulfidation of the dried $\mathrm{Co} / \mathrm{Al}_{2} \mathrm{O}_{3}$ oxidic sample. Those parameters were obtained by least square fitting of the filtered EXAFS spectra resulting from a back Fourier transform over 1-3.8 $\AA$ (Sulfide 1) and 1-2.8 $\AA$ (Sulfide 2) of the Fourier transforms of the experimental EXAFS spectra ( $k_{\min }=2.8 \AA^{-1}$ and $k_{\max }=10.6 \AA^{-1}$, Kaiser Bessel window with $\left.d k=2\right) . S_{0}^{2}=$ $0.71, \mathrm{~N}$, coordination numbers, $\mathrm{R}$, distances between Co and neighbouring atoms, $\sigma$, Debye Waller factor, enot, scaling energy parameter. The reliability of the fit was assessed by the minimization of the reduced $\chi^{2}$ red and $R_{f}$ metrics defined by the IXS standards and criteria committee (http://ixs.iit.edu/subcommittee reports/sc/err-rep.pdf). The mean distances determined from the crystallographic structure for $\mathrm{CoS}_{2}$ and $\mathrm{Co}_{9} \mathrm{~S}_{8}$ are reported for comparison purpose.

\begin{tabular}{|c|c|c|c|c|c|c|}
\hline & $\mathrm{N}$ & $\mathrm{R}(\AA)$ & $\sigma^{2}\left(10^{-3} \AA^{2}\right)$ & $\begin{array}{c}\text { enot } \\
(\mathrm{eV})\end{array}$ & $\mathrm{R}_{\mathrm{f}}(\%)$ & $\chi_{\text {red }}^{2}$ \\
\hline Co-S & $4.7 \pm 0.6$ & $2.22 \pm 0.01$ & $7.8 \pm 1.6$ & -5.2 & 0.3 & 630.6 \\
\hline Co-Mo & $0.9 \pm 0.4$ & $2.84 \pm 0.03$ & $7.6 \pm 10$ & -5.2 & \\
\hline
\end{tabular}

Table 2: Structural parameters determined by least square fitting of the filtered EXAFS spectrum (back Fourier transform over 1-3 $\AA$ ) isolated for the second component by MCR-ALS analysis of the data recorded upon sulfidation of the CoNiMo oxidic catalyst precursor supported on alumina using the CWA strategy. $\mathrm{S}_{0}{ }^{2}=0.71, \mathrm{~N}$, coordination numbers, $\mathrm{R}$, distances between Co and neighbouring atoms, $\sigma$, Debye Waller factor, enot, scaling energy parameter. The reliability of the fit was assessed by the minimization of the reduced $\chi^{2}$ red and $R_{f}$ metrics defined by the IXS standards and criteria committee (http://ixs.iit.edu/subcommittee reports/sc/err-rep.pdf). 


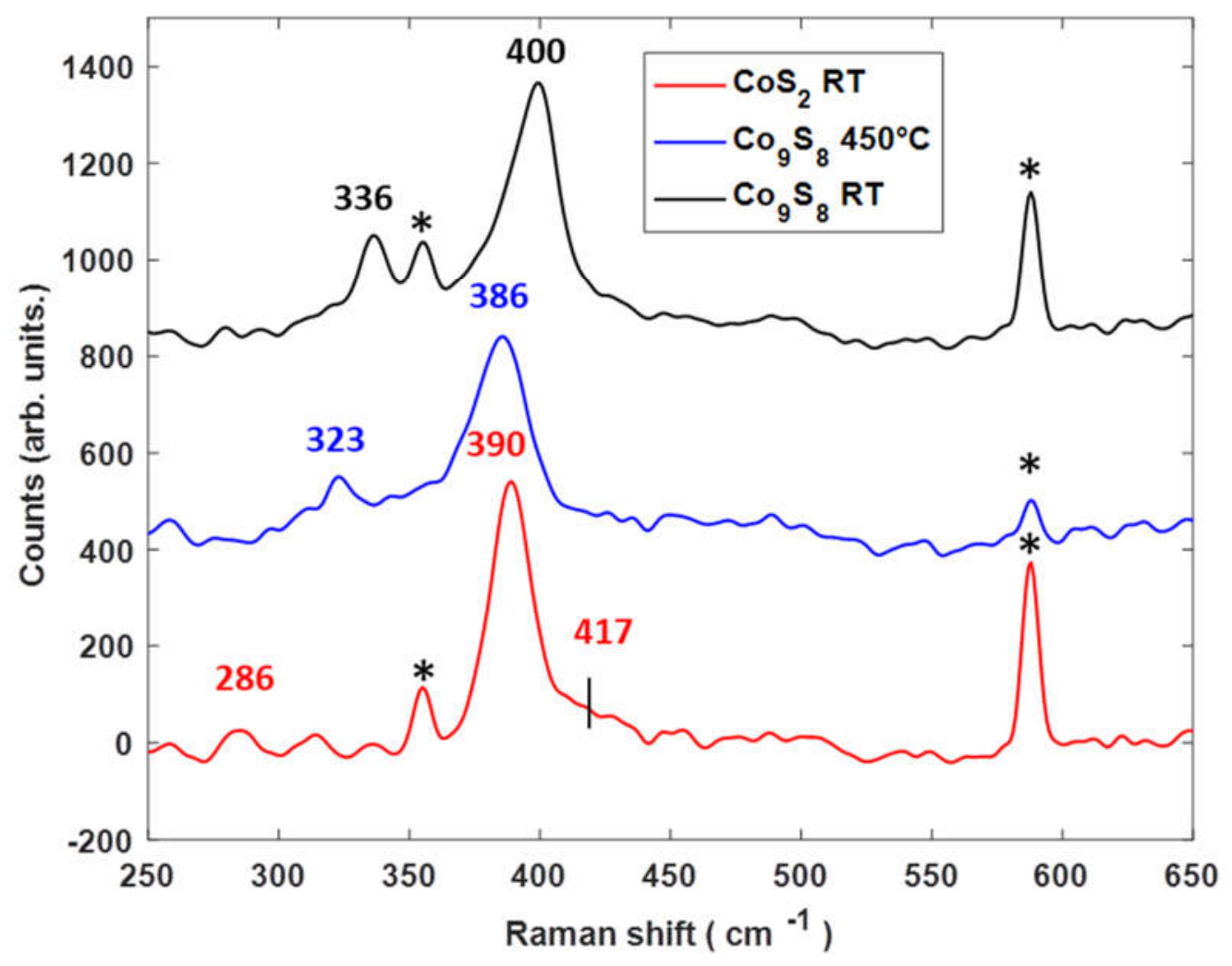

Figure 1: Raman spectra of bulk $\operatorname{CoS}_{2}$ and bulk $\mathrm{Co}_{9} \mathrm{~S}_{8}$ prepared by solid-gas reaction of bulk $\operatorname{CoS}_{2}$ under $0.5 \% \mathrm{H}_{2} \mathrm{~S} / \mathrm{H}_{2}$. The stars indicate the lines of gaseous $\mathrm{H}_{2}$. Laser excitation: $532 \mathrm{~nm}$. Average over 6 spectra with integration time: $30 \mathrm{sec} / \mathrm{spectrum}$.

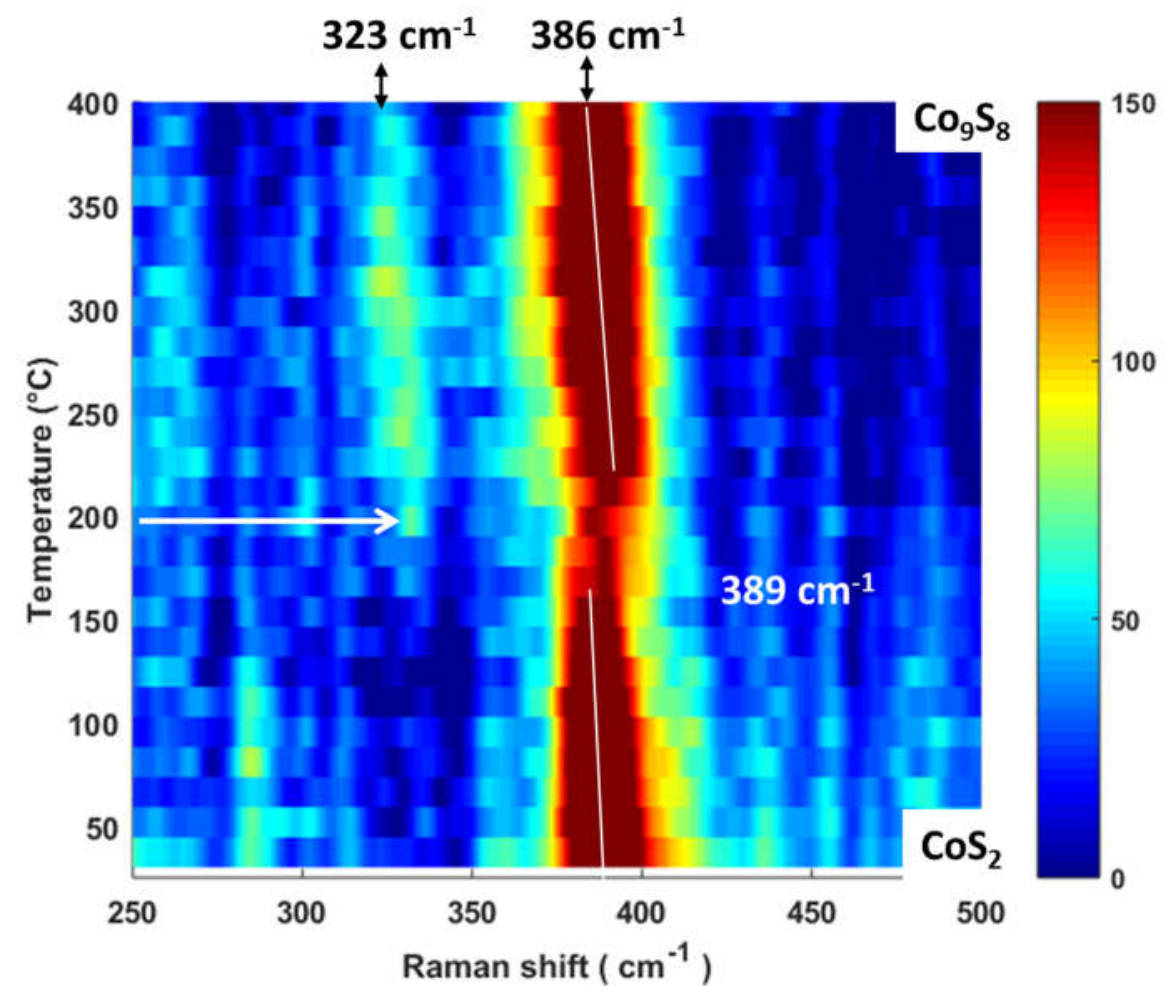

Figure 2: Raman intensity map over the cell temperature upon solid-gas reaction of bulk $\mathrm{CoS}_{2}$ under $0.5 \% \mathrm{H}_{2} \mathrm{~S} / \mathrm{H}_{2}$. Laser excitation: $532 \mathrm{~nm}$ Average over 3 spectra with integration time: 30 $\mathrm{sec} / \mathrm{spectrum}$. The increase of yellow signal around $326 \mathrm{~cm}^{-1}$ used as fingerprint of the formation of $\mathrm{Co}_{9} \mathrm{~S}_{8}$ starts around $200^{\circ} \mathrm{C}$. The color bar is related to the measured counts. 


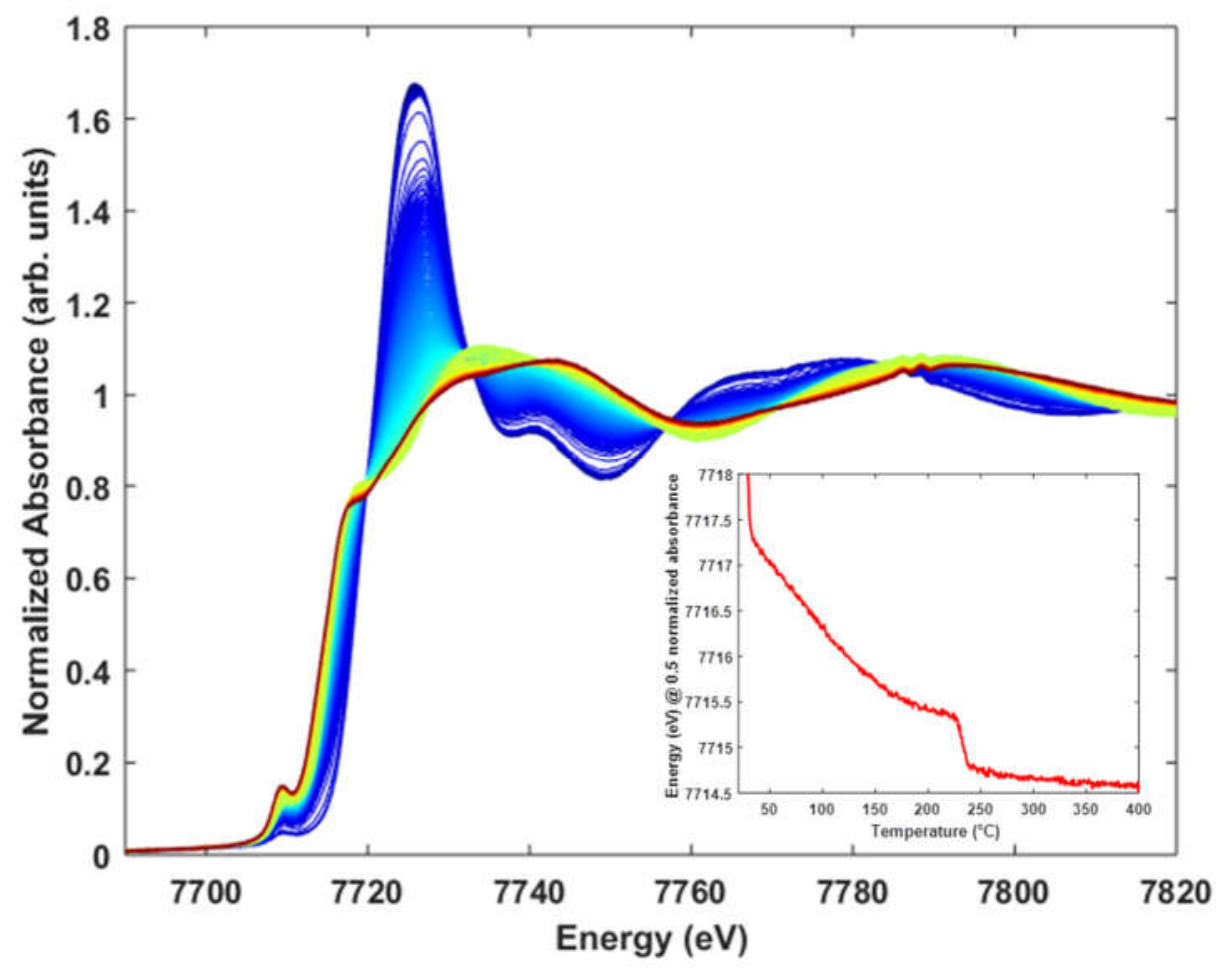

Figure 3: Evolution of the quick-XAS spectra recorded at the $\mathrm{Co} \mathrm{K}$ edge during the heating at $5^{\circ} \mathrm{C} / \mathrm{min}$ from RT to $400^{\circ} \mathrm{C}$ under $10 \% \mathrm{H}_{2} \mathrm{~S} / \mathrm{H}_{2}$ gaseous mixture of the dried $\mathrm{Co} / \mathrm{Al}_{2} \mathrm{O}_{3}$ sample. The temperature increases from the deep blue color $\left(30^{\circ} \mathrm{C}\right)$ to the deep red one $\left(400^{\circ} \mathrm{C}\right)$. The inset displays as a function of the sulfidation temperature the energy position at a normalized absorbance in the rising edge equal to 0.5 . 

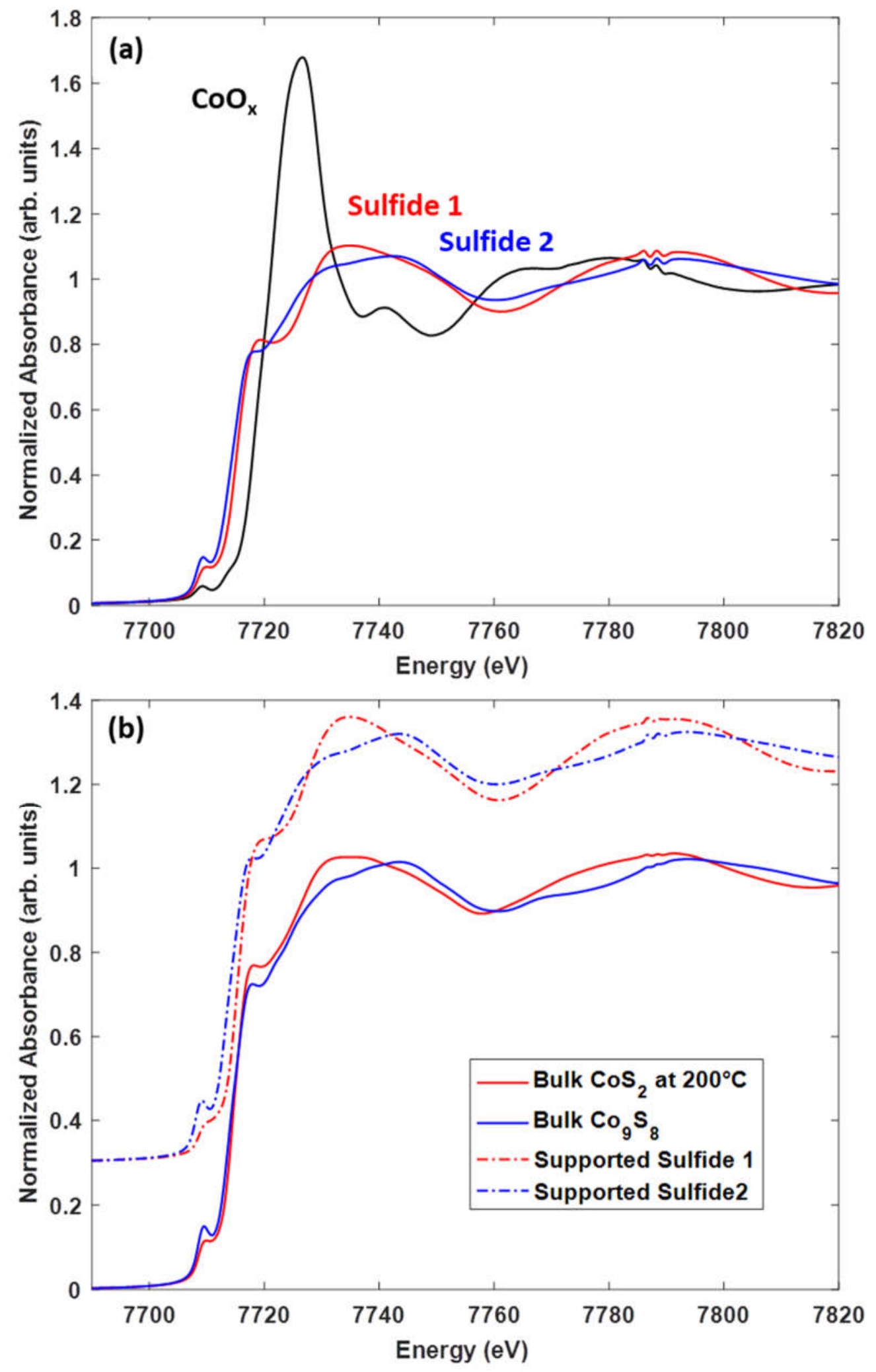

Figure 4: (a) XANES spectra associated to the MCR-ALS components determined from the analysis of the data set presented in Figure 3 and (b) comparison of the MCR-ALS XANES spectra reported for both sulfide species with the ones recorded for bulk $\mathrm{CoS}_{2}$ and bulk $\mathrm{Co}_{9} \mathrm{~S}_{8}$. 

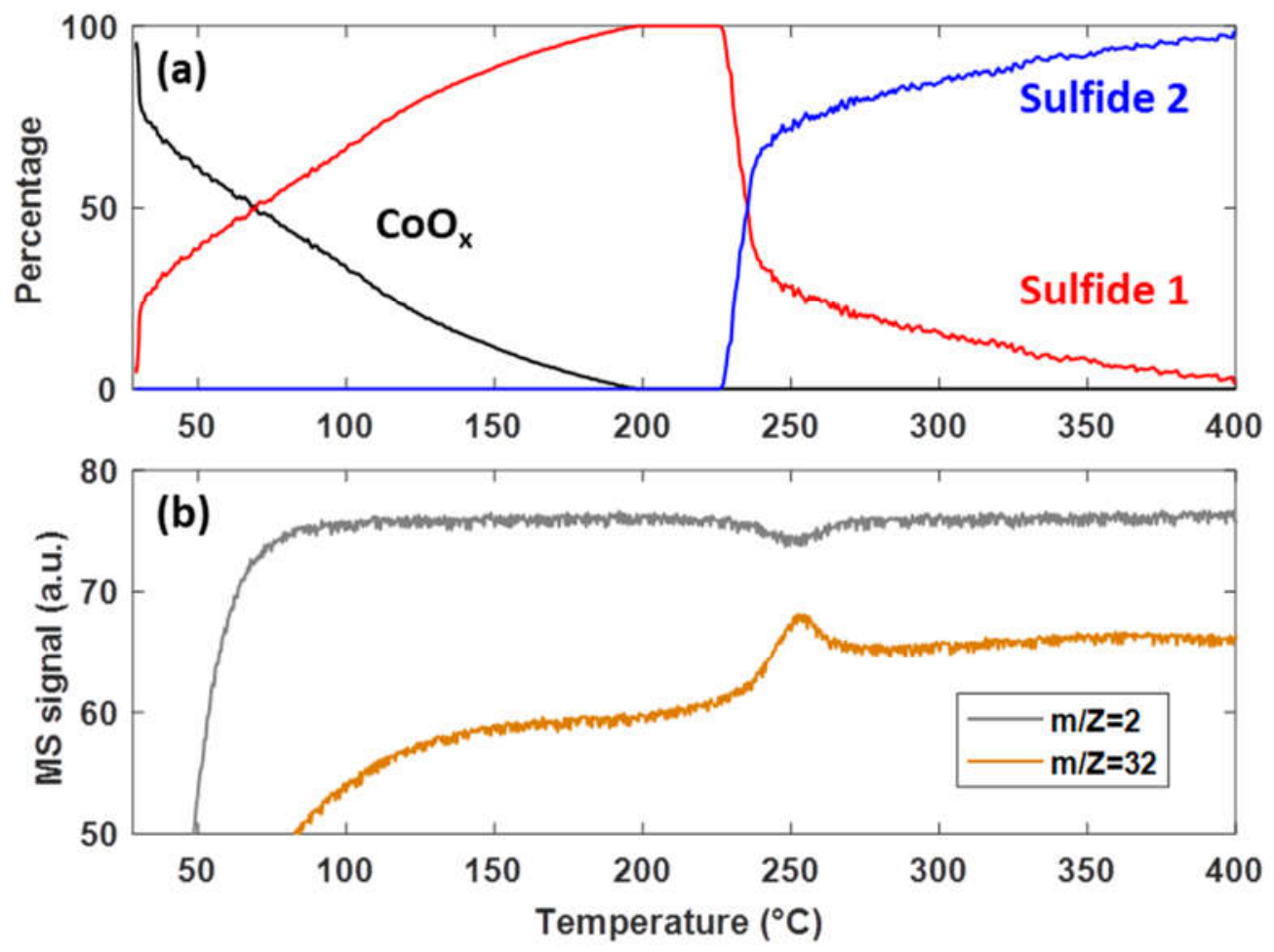

Figure 5: Evolution as a function of temperature (a) of the concentration of the Co species isolated by MCR-ALS (LOF $=0.37 \%$ ) from the analysis of the data set presented in Figure 3 and identified as supported $\mathrm{CoO}_{x}$ (black), $\mathrm{CoS}_{2}$ (red) and $\mathrm{Co}_{9} \mathrm{~S}_{8}$ (blue) and (b) of the $\mathrm{m} / \mathrm{Z}$ signals recorded for $\mathrm{H}_{2}$ and $\mathrm{H}_{2} \mathrm{~S}$ by mass spectrometry. 

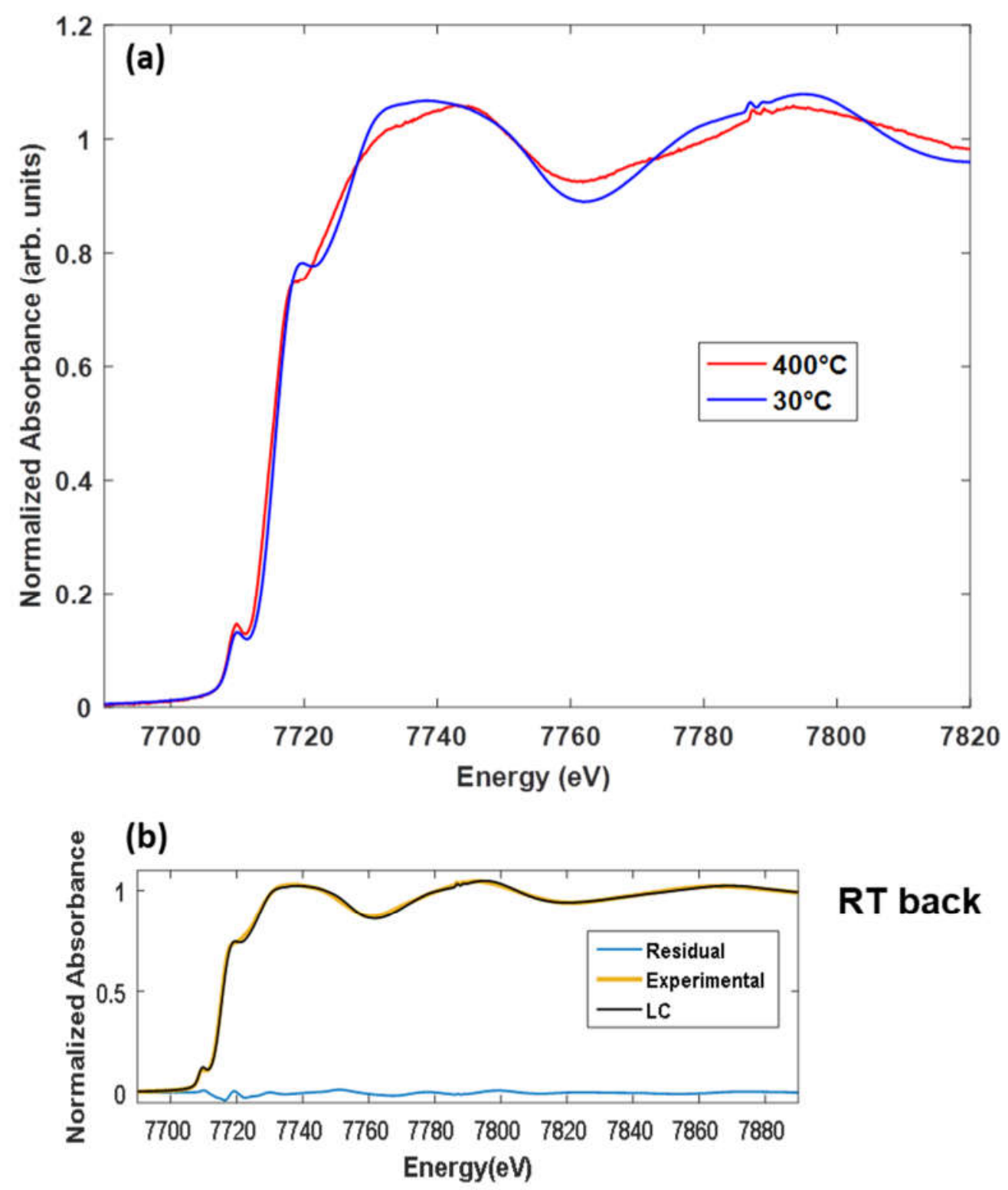

\section{RT back}

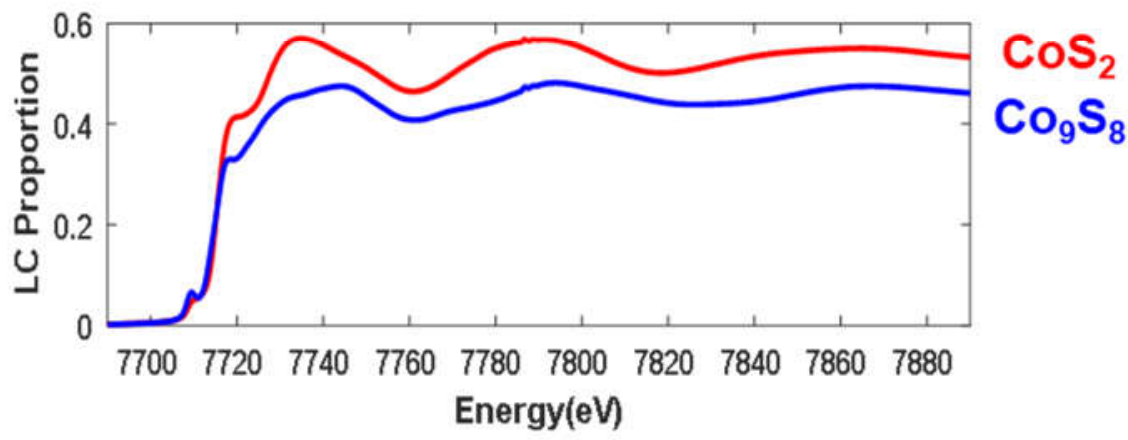

Figure 6: (a) Comparison of the XANES spectra recorded at $400^{\circ} \mathrm{C}$ after sulfidation of the dried $\mathrm{Co} / \mathrm{Al}_{2} \mathrm{O}_{3}$ sample and at $30^{\circ} \mathrm{C}$ after cooling down the cell under $\mathrm{H}_{2} \mathrm{~S} / \mathrm{H}_{2}$ gaseous mixture. (b) Linear combination fitting for rebuilding the XANES spectrum of the sample after the cooling to room temperature leading to a proportion of $46.0 \pm 1.1 \%$ of $\mathrm{Co}_{9} \mathrm{~S}_{8}$ and $54.0 \pm 1.1 \% \operatorname{CoS}_{2}\left(R_{f}=0.91 \%\right)$. 


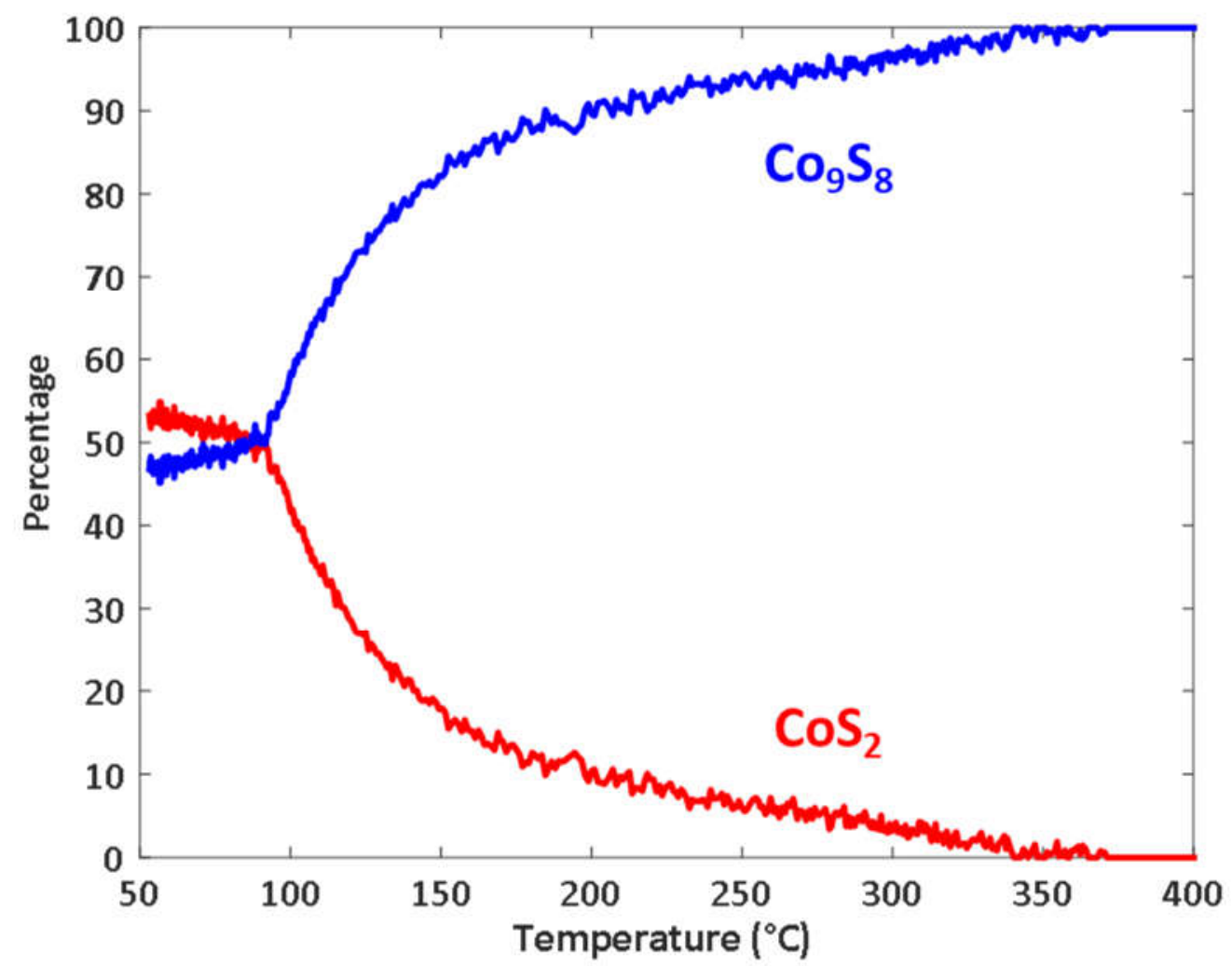

Figure 7: Evolution of concentration profiles determined by MCR-ALS for the XAS data recorded for the sulfided dried $\mathrm{Co} / \mathrm{Al}_{2} \mathrm{O}_{3}$ sample when the temperature is decreased from 400 to $30^{\circ} \mathrm{C}$ under $10 \%$ $\mathrm{H}_{2} \mathrm{~S}$ - $\mathrm{H}_{2}$ gaseous mixture. LOF $=0.64 \%$ and percent of variance explained $=99.9996 \%$.

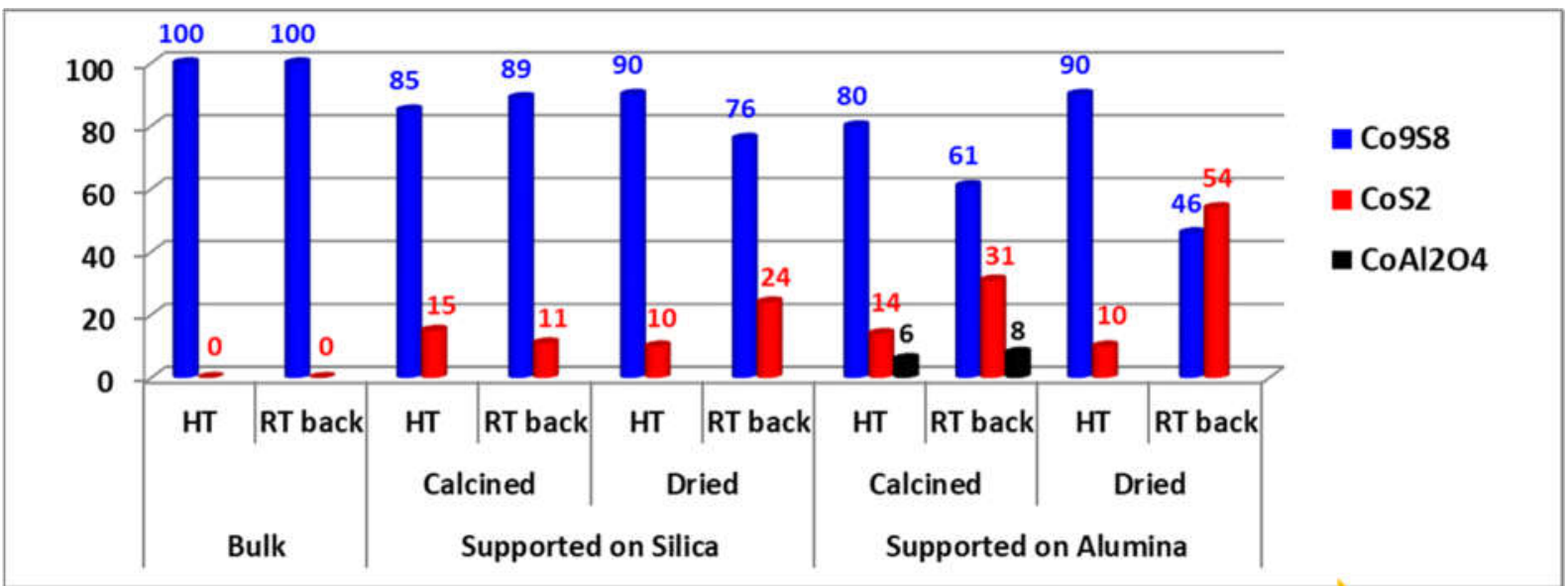

\section{Decreasing Crystallite Size}

Figure 8: Percentage of cobalt species obtained by linear combination fitting for rebuilding the XANES spectra of the different samples recorded at the end of the thermal treatment, at $400^{\circ} \mathrm{C}$ or $450^{\circ} \mathrm{C}$ labelled $\mathrm{HT}$, and after cooling down under $\mathrm{H}_{2} \mathrm{~S} / \mathrm{H}_{2}$ gaseous mixture up to RT, labelled RT back. The sulfidation of supported samples was carried out with a heating ramp of $3^{\circ} \mathrm{C} / \mathrm{min}$. The average error bar for the percentage is $1.5 \%$. 

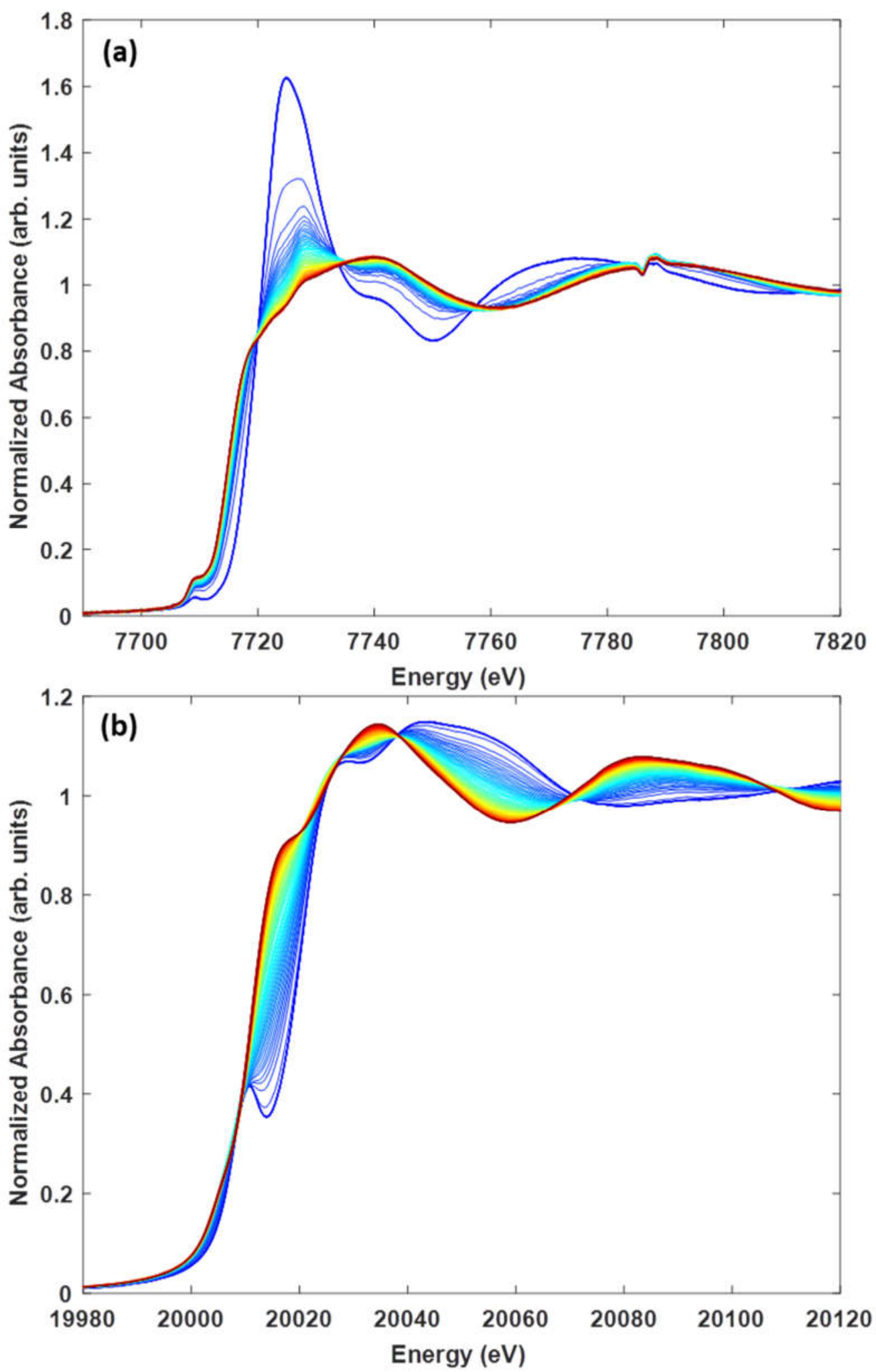

Figure 9: Evolution of the quick-XAS spectra recorded at the Co $\mathrm{K}(\mathrm{a})$ and $\mathrm{Mo} \mathrm{K}(\mathrm{b})$ edges during the heating at $3^{\circ} \mathrm{C} / \mathrm{min}$ from RT to $400^{\circ} \mathrm{C}$ under $10 \% \mathrm{H}_{2} \mathrm{~S} / 90 \% \mathrm{H}_{2}$ gaseous mixture of the calcined $\mathrm{CoNiMo} / \mathrm{Al}_{2} \mathrm{O}_{3}$ oxidic catalyst precursor. The temperature increases from the deep blue color $\left(30^{\circ} \mathrm{C}\right)$ to the deep red one $\left(400^{\circ} \mathrm{C}\right)$. 

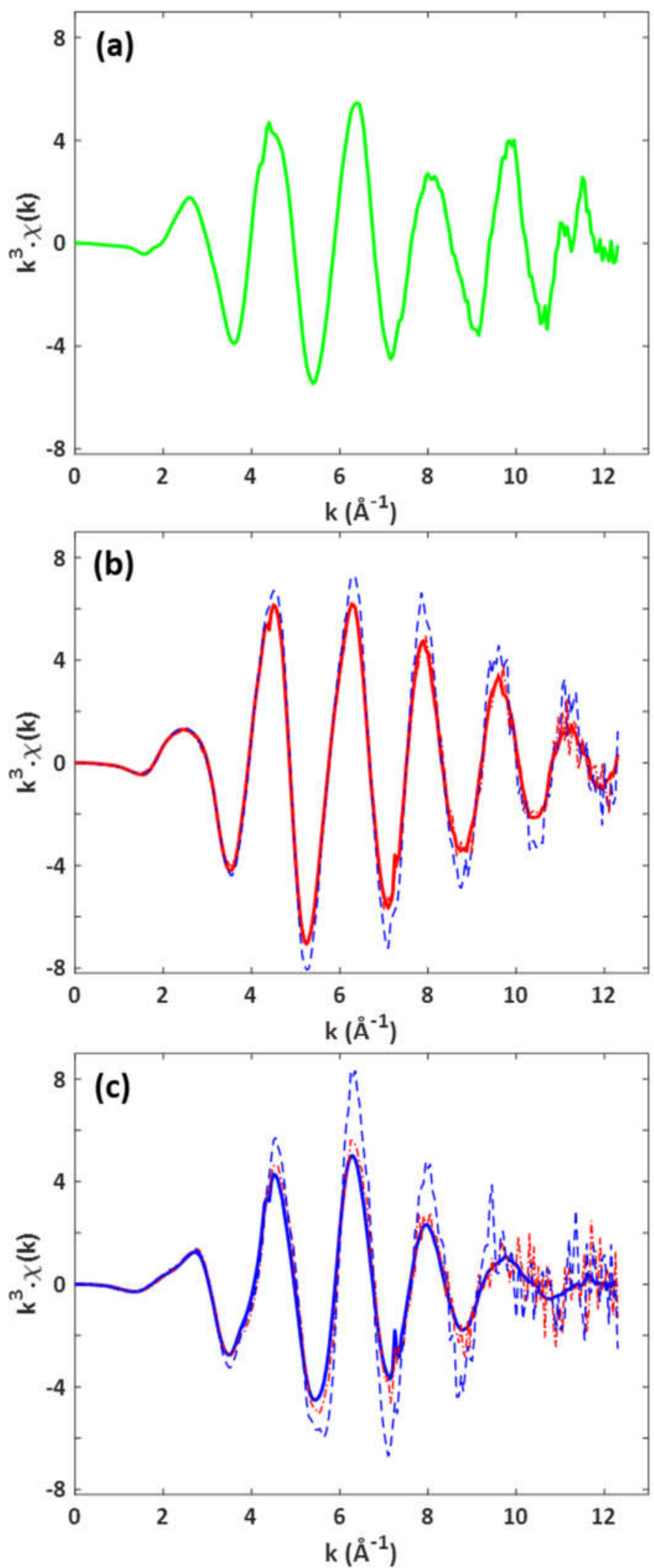

Figure 10: EXAFS spectra of the sulfide-based cobalt species isolated by CWA-MCR-ALS analysis of the Co $\mathrm{K}$ edge quick-XAS spectra recorded during the sulfidation of the CoNiMo HDS catalyst: (a) $2^{\text {nd }}$ component identified as a CoMoS species, (b) $3^{\text {rd }}$ component (red line) identified as $\mathrm{CoS}_{2}$ by comparison with the experimental spectra recorded at $200^{\circ} \mathrm{C}$ (red dashed line) during the sulfidation of the dried $\mathrm{Co} / \mathrm{Al}_{2} \mathrm{O}_{3}$ sample and at RT (blue dashed line, cooling under $\mathrm{H}_{2} \mathrm{~S} / \mathrm{H}_{2}$ ), (c) $4^{\text {th }}$ component 
(blue line) identified as $\mathrm{Co}_{9} \mathrm{~S}_{8}$ by comparison with the experimental spectra recorded at $400^{\circ} \mathrm{C}$ (red dashed line) during the sulfidation of the dried $\mathrm{Co} / \mathrm{Al}_{2} \mathrm{O}_{3}$ sample and at $\mathrm{RT}$ (blue dashed line, cooling under argon).

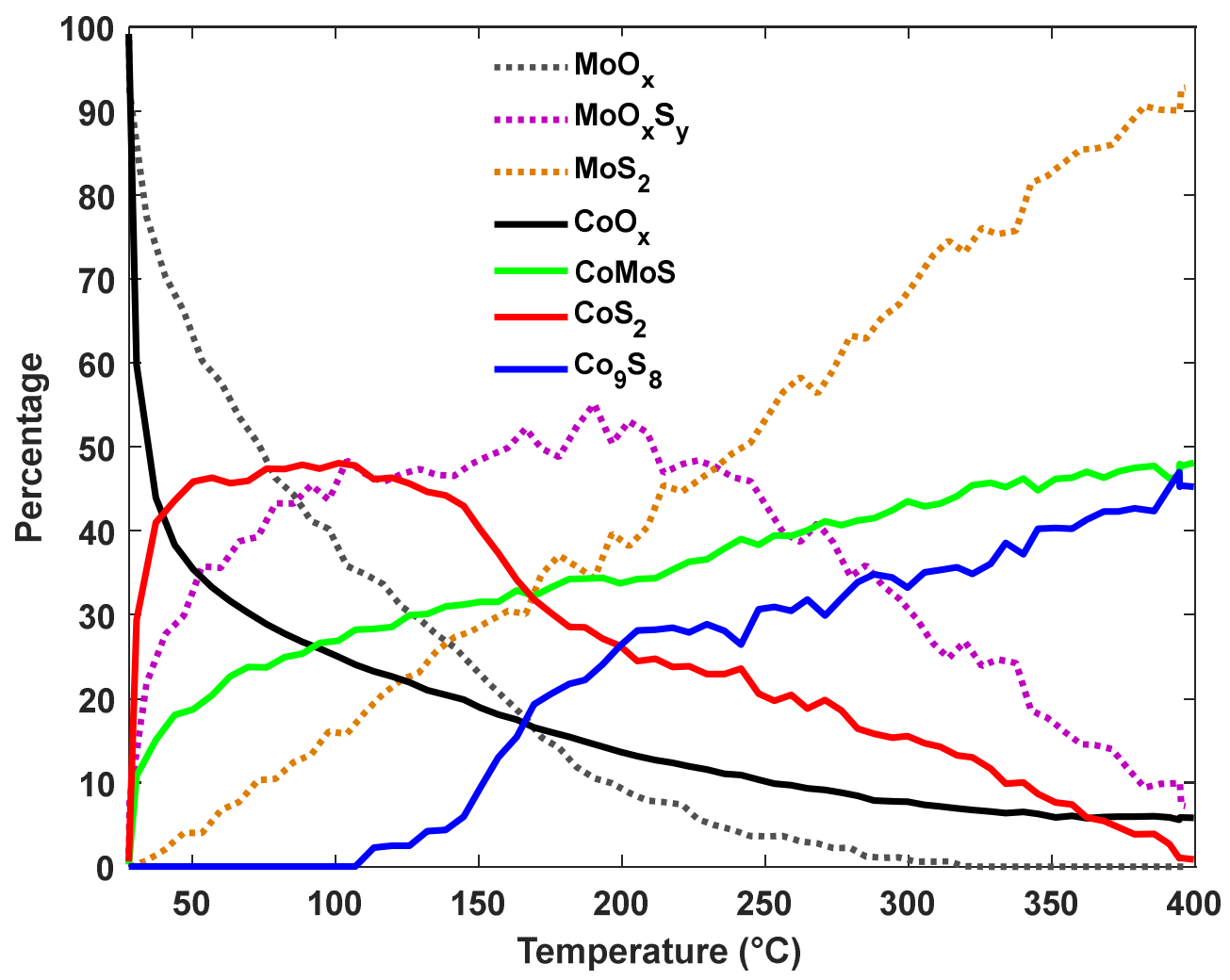

Figure 11: Comparison of the evolution of the percentage of the Co and Mo species isolated by MCRALS from the analysis of the $\mathrm{CoNiMo} / \mathrm{Al}_{2} \mathrm{O}_{3}$ data set presented in Figure 9 and identified as supported $\mathrm{CoO}_{x}$ (black), $\mathrm{CoS}_{2}$ (red), $\mathrm{Co}_{9} \mathrm{~S}_{8}$ (blue) and $\mathrm{CoMoS}$ (green) for the Co-based species and $\mathrm{MoO}_{\mathrm{x}}$ (grey), $\mathrm{MoO}_{x} \mathrm{~S}_{y}$ (purple) and $\mathrm{MoS}_{2}$ (orange) for the Mo-based species. 


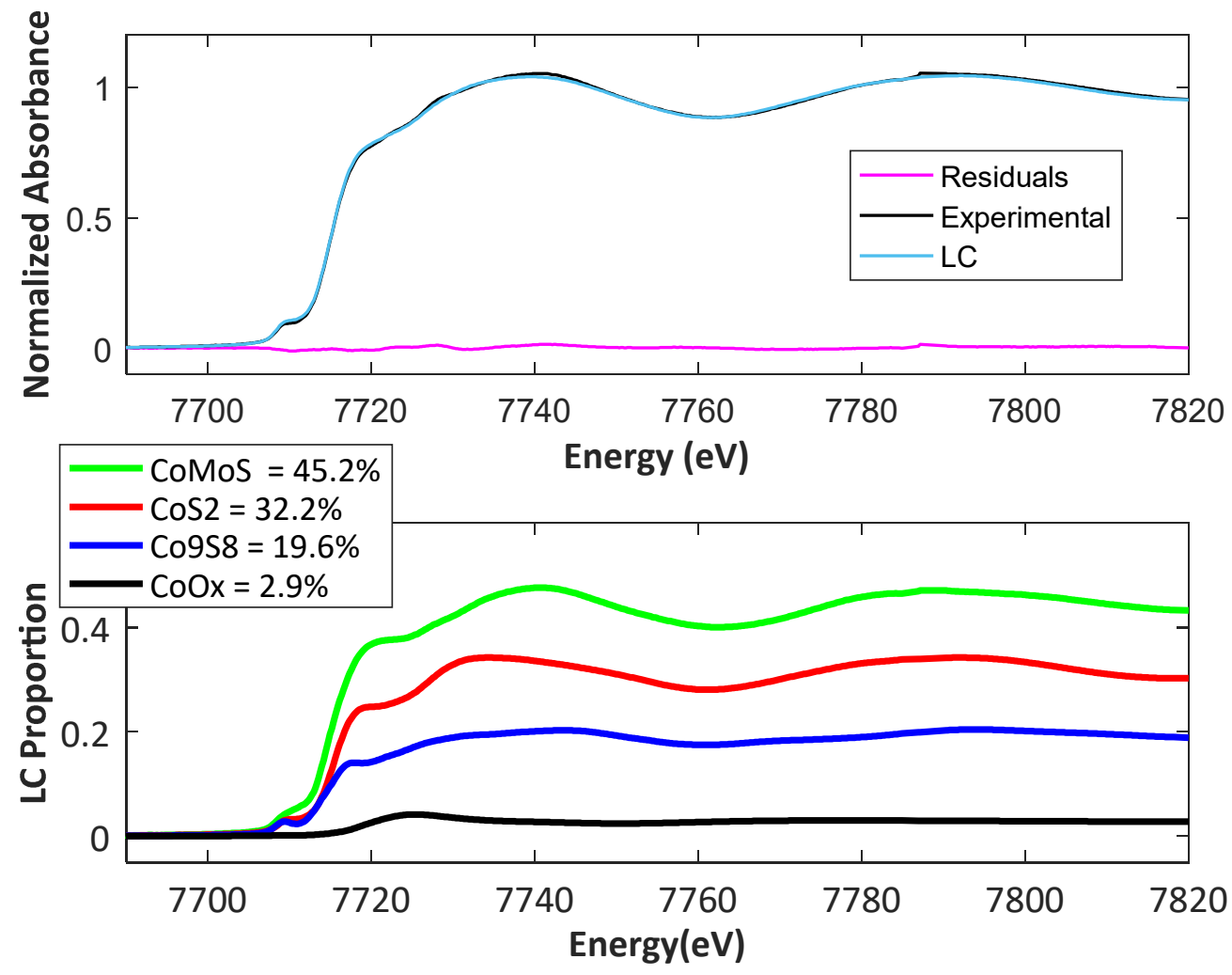

Figure 12: Linear combination fitting (red line) for rebuilding the RT XANES spectrum of the calcined $\mathrm{CoNiMo} / \mathrm{Al}_{2} \mathrm{O}_{3}$ (black line) after sulfidation under $10 \% \quad \mathrm{H}_{2} \mathrm{~S}-\mathrm{H}_{2}$ gaseous mixture leading to the proportion of $45.2 \pm 1.1 \%$ of CoMoS species, $32.2 \pm 0.8 \%$ of supported $\operatorname{CoS}_{2}, 19.6 \pm 0.8 \%$ of supported $\mathrm{Co}_{9} \mathrm{~S}_{8}$ and $2.9 \pm 1.6 \%$ of $\mathrm{CoO}_{x}\left(R_{f}=0.52 \%\right)$. 